\title{
Cardiac Sarcolemmal Defects in Acute Myocarditis Due to Scorpion Envenoming Syndrome
}

\author{
K. Radha Krishna Murthy \\ Department of Physiology, Santhiram General Hospital \& Santhiram Medical College, Kurnool District, \\ India \\ Email: kradhakrishnamurthy@yahoo.com
}

Received 3 May 2014; revised 18 June 2014; accepted 22 July 2014

Copyright (C) 2014 by author and Scientific Research Publishing Inc. This work is licensed under the Creative Commons Attribution International License (CC BY). http://creativecommons.org/licenses/by/4.0/

(c) (i) Open Access

\section{Abstract}

Death due to scorpion envenoming syndrome is a common event in tropical and subtropical countries. Severe scorpion envenoming causes autonomic storm, massive release of catecholamines, counter-regulatory hormones, suppressed insulin/hyperinsulinemia, acute myocarditis, hyperglycemia, increased free fatty Acid levels, acute pancreatitis, disseminated intra-vascular coagulation, acute pulmonary oedema and death. Severe scorpion envenoming causes cardiac sarcolemmal defects displayed by alterations in $\mathrm{Na}^{+}-\mathrm{K}^{+}$ATPase, $\mathrm{Mg}^{++}$ATPase and $\mathrm{Ca}^{2+}$ ATPase activities, inhibition of erythrocyte $\mathrm{Na}^{+}-\mathrm{K}^{+}$ATPase activities, hyperkalemia and may result in death. Based on our animal experiments in which insulin administration reversed the metabolic and ECG changes induced by scorpion envenoming and treating the poisonous scorpion sting victims with insulin, we consider that insulin has a primary metabolic role in preventing and reversing acute myocarditis, the cardiovascular, haemodynamic, and neurological manifestations and pulmonary oedema induced by scorpion envenoming. Administration of insulin-glucose infusion to scorpion sting victims appears to be the physiological basis for the control of the metabolic response when that has become a determinant to survival. Continuous infusion of regular crystalline insulin should be given at the rate of $0.3 \mathrm{U} / \mathrm{g}$ glucose and glucose at the rate of $0.1 \mathrm{~g} / \mathrm{kg}$ body weight/hour, for 48 - 72 hours, with supplementation of potassium as needed and maintenance of fluid, electrolytes and acid-base balance. The observation of cardiac sarcolemmal defects and physiological basis of various patho-physiological mechanisms involved in the genesis of scorpion envenoming syndrome and its reversal (in the experimental animals and scorpion sting victims) by administration of insulin are reviewed.

\section{Keywords}

Scorpion Envenoming Syndrome, Suppressed Insulin Secretion, Inhibition of $\mathrm{Na}^{+}-\mathrm{K}^{+}$ATPase 


\section{Introduction}

The treatment of scorpion envenoming syndrome is a difficult problem. Scorpion envenoming syndrome requires extensive knowledge of the clinical manifestations and an understanding of the mechanisms behind the clinical symptomatology. The experimental basis of Cardiac Sarcolemmal Defects in Acute Myocarditis and various patho-physiological mechanisms involved in the genesis of scorpion envenoming syndrome and its reversal (in the experimental animals and scorpion sting victims) by administration of insulin is reviewed.

\subsection{Death Due to Scorpion Envenoming Syndrome Is a Common Event All over the World}

Death due to scorpion envenoming syndrome is a common event all over the world especially in tropical and sub-tropical countries [1]-[15]. Scorpion envenomation is a major concern only in less developed countries where scientific and medical research has not been a priority, which might account for lack of data [16]-[30]. The estimated number of annual human envenomations in Mexico is 100,000 to 200,000, with mortalities of 500 to 1000. In Algeria, Tunisia, and Saudi Arabia, envenomations range between 24,000 and 45,000 per country and in Brazil, >7000 envenomations occur per year. Scorpion stings are also common in China, India, Iraq, Iran, Saudi Arabia, Middle East, and Central and South Africa, although the exact number of victims and deaths are unknown [31]-[39].

\subsection{Problem of Scorpion Envenoming Syndrome Has Been either Ignored or Neglected by the International Scientific Community}

Scorpion sting is a rural emergency occurring in villages where medical facilities are not available (for example in a country like India). The consequences of scorpion envenoming syndrome have been underestimated in health statistic of these developing countries due to inadequate detection and/or data entry of the cases. There is not even a "guesstimate" regarding the number of deaths due to these "nocturnal visitors" especially in a country like India!

India harbors about 55 most dangerous killer species of scorpions that belong to Buthidae family. Thousands of scorpion sting victims die annually in India! Local governments, State Governments (Andhra Pradesh, Karnataka, Tamil Nadu, west Bengal, Bihar, Gujarat, Rajasthan, Uttar Pradesh, Madhya Pradesh, Maharashtra and many more States) and Central Government of India did not take any concrete measures to tackle the scorpion envenoming syndrome in India [1]-[4] [9] [10] [20]-[39]. The problem of scorpion envenoming syndrome has been either ignored or neglected by the international scientific community [19].

Most of the standard textbooks of Physiology [40] [41], Pharmacology [42], Medicine [43]-[49] dismiss the scorpion envenoming syndrome in few lines! Most of these standard textbooks completely ignore scorpion envenoming syndrome! Very little or "no clinical information" useful to the physician to manage and treat a victim of severe scorpion envenoming syndrome is provided in these textbooks [43]-[50]!

\subsection{Buthidae Family—Highly Toxic Venomous Scorpions of the World}

The highly toxic venomous scorpions of the world belong to Androctonus, Buthus, Centruroides, Leiurus Quinquestriatus, Tityus genera and come under Buthidae family.

Signs and symptoms following stings by scorpions of Buthidae family, all over the world, are remarkably similar.

In spite of many zoological differences in the scorpions belonging to Buthidae family and differences in the chemical structure of venoms, symptomatology in humans following scorpion envenoming by scorpion stings of Buthidae family, throughout the world, is quite similar [1]-[37].

The clinical presentation of scorpion sting victims (Mesobuthus tamulus concanesis, Pocock [34] [37] from India or clinical data of scorpion sting patients with severe scorpion envenoming caused by Tityus serrulatus [5]-[7] or Tityus bahiensis from Brazil [12] or clinical manifestations of scorpion sting patients (Leiurus quinquestriatus) from Israel [14] [15], or Buthus occitanus envenomation from Tunisia [7] or yellow scorpion Lei- 
urus quinquestriatus from Saudi Arabia [16]-[19], or from West Indies [11] [51] are similar.

Clinical manifestations following stings by dangerous scorpions of Buthidae family, all over the world, are remarkably similar and may involve the central nervous system (CNS), the autonomic nervous system (the Sympathetic as well Para-sympathetic systems of the autonomic nervous system), the respiratory tract, the pancreas (exocrine as well as endocrine pancreatic systems), and the cardio-vascular system in the experimental animals and scorpion sting victims producing scorpion envenoming syndrome [1]-[7] [11]-[19] [34] [37].

\subsection{Myocardial Damage as Evidenced by Electrocardiographic, Enzymatic and Echocardiographic Studies after Scorpion Envenoming, throughout the World, Is Similar}

Electrocardiographic changes, hematological changes-leucocytosis, increase in RBC count, increase in PCV, MCV, MCH, MCHC, Hb, appearance of Plasma HB in the experimental animals with acute myocarditis from India [8]-[10] [19]-[25] [29]-[31] [33] [34] [36] [37], ECG, enzymatic and echocardiographic evidence of myocardial damage after poisoning by scorpion Titus serrulatus from Brazil [5]-[7] [13] or observations of high blood pressure, enzymes and radionuclide angiograms on admission of scorpion sting (Leiurus quinquestriatus) victims from Israel [14] [15] [52]-[54] or neurological complications secondary to severe scorpion envenomation from scorpion Androctonus australis and Buthus occitanus envenomation from Tunisia [7], or yellow scorpion Leiurus quinquestriatus from Saudi Arabia [16]-[19], or from West Indies [11] [51] are similar.

The review article is discussed under the following major headings:

1) Acute myocarditis-myocardial damage evidenced by Electrocardiographic, Enzymatic and Echocardiographic Studies;

2) Acute myocarditis and cardiac enzymes;

3) Acute myocarditis and autonomic storm;

4) Acute myocarditis-sudden increase in free fatty acids;

5) Acute myocarditis-cardiac sarcolemma;

6) Administration of insulin;

7) The drugs/either not useful or contra-indicated.

\section{Acute Myocarditis-Myocardial Damage as Evidenced by Electrocardiographic, Enzymatic and Echocardiographic Studies}

\subsection{Acute Myocarditis}

The ECG is the most important laboratory aid in the diagnosis of acute myocarditis and in those cases where clinical manifestations are absent; the diagnosis may rest entirely on the findings of ECG [43]-[51].

\subsection{Abnormal ECG Changes after Envenoming}

Scorpion sting myocardial toxicity is more common than neurotoxicity and often is the cause of death. Acute myocarditis is frequently unrecognized because of the severity of the associated condition. In myocarditis, the ECG may show atrial and ventricular extra systoles, arrhythmias, conduction disturbances and ST-T wave abnormalities [21]-[30] [33] [34] [37].

The scorpion venom is a powerful arrhythmogenic agent by virtue of stimulating autonomic sympathetic system and adrenal glands. The common immediate arrhythmias are sinus arrest or sinus bradycardia with different escape rhythms (for example: Junctional rhythm), premature ventricular tachycardia. Each one of these has been recorded by us. Further, the arrhythmias were present before the full hemodynamic venom induced effects [29].

Many abnormal ECG changes were observed after envenoming. These include early myocardial infarction like pattern with ST segment elevation, ST segment depression, presence of Q waves. These abnormalities were observed within a fraction of a minute after administration of the scorpion venom. In addition to these changes, there were: Rhythm disturbances such as AV disassociation, SA Block, Atrial tachycardia and Ventricular tachycardia, Bundle branch block and Pericarditis like patterns [9] [10] [21]-[28] [31] [33] [34] [37] [56].

\subsection{ECG Changes in Our Experimental Animals}

We observed several abnormalities in the electrocardiographic tracings pertaining to changes in the configura- 
tion of complexes, conduction defects at various levels and arrthymias of several types in the experimental animals after intravenous injection of $4 \mathrm{mg} / \mathrm{kg}$ venom from scorpion (Mesobuthus tamulus Concanesis, Pocock. The abnormalities included sinus bradycardia, sinus tachycardia, prolonged PR interval, Short PR interval, and abnormal “Q” wave, narrow QRS, broad QRS of intra-ventricular conduction defect type, Bundle Branch Block pattern, flat T wave, inverted T wave, ST segment elevation and ST segment depression, myocardial infarction like pattern. ECG tracings also showed change of axis, electrical alternans, first degree heart block, junctional rhythm, atrial and ventricular fibrillation [29]. We have recorded myocardial infarction like pattern, junctional rhythm and electrical alternans hitherto unreported in experimental myocarditis due to Mesobuthus tamulus Concanesis, Pocock (earlier known as Indian red scorpion of Buthus tamulus) but reported in human victims in 1986! Change of axis in the ECG tracings noticed by us has not been reported either in the experimental studies or in patients affected by scorpion stings. We claim to have recorded almost all ECG changes (in the experimental studies) noticed in humans affected by scorpion stings [29].

We have observed the following ECG changes in the rabbits after scorpion envenoming [22]. Hyperacute injury pattern with ST elevation, ventricular tachycardia, sinus tachycardia with ST-T changes, acute infarction, sinus arrest, infarction like pattern, runs of ventricular premature beats, multi-focal ventricular premature beats [9] [10] [29].

We have recorded the following ECG abnormalities in our experimental animals with "acute myocarditis" in scorpion envenoming syndrome.

Electrocardiographic changes reported in the experimentally induced myocarditis by the poisonous scorpion venom injection have been: 1) sinus tachycardia, 2) sinus bradycardia, 3) T inversion, 4) ST elevation, 5) ST depression, 6) AV conduction defects with sinus arrest, 7) Ventricular premature contraction, 8) T wave configuration changes, 9) Prolonged PR, 10) Short PR, 11) ST depression, 12) Narrow QRS, a) Wide QRS and b) Extra systoles [9] [10] [21]-[29] [31] [33] [34] [37] [39] [56].

\subsubsection{Scorpion Envenoming \& ECG Changes in Our Experimental Animals}

We have reported myocardial infarction like pattern with ST elevation, ventricular tachycardia, sinus tachycardia with ST-T changes, acute infarction, sinus arrest, infarction like pattern, runs of ventricular premature beats, multi-focal ventricular premature beats [9] [10] [21] [29].

\subsubsection{ECG Changes Observed in Our Experimental Dogs [22]-[31] [33] [34] [37] [39] [56]}

\section{Myocardial infarction like pattern}

Escape Beats \& Escape Rhythms: junction rhythm, junction escape, ventricular escape

Premature Systoles \& Para Systoles: APC, bigeminy, junctional extra systoles, VPC

Paroxysmal \& Non-paroxysmal Tachycardia: nodal tachycardia, ventricular tachycardia

Fibrillation \& Flutter: Ventricular fibrillation

Conduction Block: S-A block, A-V dissociation, Bundle branch block, Wide QRS

Other disturbances in ECG: Sinus tachycardia, Sinus bradycardia, Absent P wave, Axis change, Voltage changes, Electrical alternans, ST depression, ST elevation, Infarction like pattern, T flat/T inversion.

\subsubsection{After Insulin Administration}

ECG changes and arrhythmias were not noticed after insulin administration in $68 \%$ of the animals whereas in the remaining 32\% of the animals it took 20 minutes after insulin administration for the arrhythmias like nodal premature contractions, first degree heart block, nodal rhythms and other changes like wide QRS, T inversion and low voltage to revert towards normal [30] [33] [34].

\subsection{Electrocardiographic Studies Using L. quinquestriatus Venom}

The i.v. injection of $L$. quinquestriatus venom $(1 \mathrm{mg} / \mathrm{kg})$ into rabbits caused an initial moderate bradycardia and immediate inversion of the $\mathrm{T}$ wave in $\mathrm{I}$. This was either accompanied or followed by inversion of $\mathrm{T}$ wave in III, aVL, aVF, $\mathrm{V}_{1}$ and $\mathrm{V}_{5}$. In most animals, the ST segment was depressed in I, II, aVL and $\mathrm{V}_{5}$. A notched R wave in I or an RSr' pattern in II was seen at the same time [17].

The bradycardia progressed with time and became very severe near the time of death, which generally occurred 10 - 50 min following venom injection. 
Other electrocardiographic abnormalities included a prominent “Q” wave in I, aVR, $V_{1}$ and $V_{5}$. Some dropped beats and occasional coupled beats. Bigemini was very prominent during the phases of marked bradycardia [17].

Tall peaked and slender $\mathrm{T}$ wave, $\mathrm{S}$ wave $>\mathrm{R}$ wave, prolonged ST interval and wide QRD complexes were frequently observed. When the venom was injected into animals maintained under artificial ventilation, neither the electrocardiographic changes nor the death time were altered [17].

\subsection{Electrocardiographic Studies Using A. amoreuxi Venom}

A. amoreuxi venom in doses lower than $0.5 \mathrm{mg} / \mathrm{kg}$ did not cause any significant ECG changes, while $1 \mathrm{mg} / \mathrm{kg}$ i.v. and higher doses caused definite changes within 30 - 120 minutes. The first effect noticed was a short-lasting bradycardia which changed to slight tachycardia after 2 - 3 min. Some arrhythmias were observed in some animals. The tachycardia was over within 5 - 15 min and was followed by bradycardia which persisted until death of the animal. The ST Segment was elevated in I, aVL and $V_{5}$ but depressed in II, III and $V_{1}, 3$ min after venom injection. Ten minutes after venom injection, the T wave was inverted in I, II, III and aVL and inverted or biphasic in $\mathrm{V}_{1}$. Some extra systoles were seen in I, II, III, and aVL. Thirty minutes after venom injection the T wave was inverted in I, aVL. The ST segment was depressed in I and V5. The inversion of the T wave in I, aVL and V1 was more prominent 60 min after venom injection. Ninety minutes after venom injection there was very marked bradycardia with prolonged P-R intervals. There was no sinus rhythm and 2:1, 3:1 and several rhythms were seen. The ST Segment was elevated in I and V5. This was accompanied in most cases by respiratory arrest leading to death of the animal [16] [17].

When the venom was injected s.c. (rabbits) or i.m. (rabbits), the onset of the electrocardiographic effects and death were delayed although the course of the change was the same as the i.v. route. The bradycardia occurred 40 - 60 min following the s.c. injection of the venom and somewhat longer following the i.m. route [16].

The rabbits showed miosis with excessive salivation, lachrymation and defecation 20 - 30 min following venom injection. Auscultation revealed humid rattle and crepitations at times of pronounced electrocardiographic changes. Postmortem examination of the animals showed large infarcted areas either in the antero-septal or inferior aspects of the heart [16].

The most striking ECG changes caused by the venom seemed to be myocardial ischemia and anterior wall infarction. The myocardial ischemia was evidenced from depression of the ST segment in II, III and $\mathrm{V}_{1}$. The anterior wall infarction was revealed from elevation of the ST segment in I, aVL and $\mathrm{V}_{5}$ and the inversion of the $\mathrm{T}$ wave in $\mathrm{I}, \mathrm{aVL}$ and $\mathrm{V}_{1}$. These changes occurred 30 - 60 minutes following venom injection [16].

\subsection{Electrolyte Changes and ECG in Scorpion Envenoming}

The ECG effects of the scorpion venom are markedly influenced by electrolyte disturbances; the effects are aggravated by hyperkalemia and hypocalcemia [17].

The cardiac effects in the experimental animals were comparable to the changes observed in human accidentally stung by scorpion. Scorpion venoms appeared to cause some of their ECG abnormalities through electrolyte changes.

We have reported hyperkalemia [24], hyperglycemia [23] [24] [30]-[33] [39] and hypocalcemia [39] in the experimental animals with scorpion envenoming.

\subsubsection{Hypocalcemia}

The prolonged ST segment or $\mathrm{QT}_{\mathrm{C}}$ interval in addition to the $\mathrm{S}$ wave $>\mathrm{R}$ wave is characteristic of Hypocalcemia. The tall and peaked $\mathrm{T}$ waves and the prolonged $\mathrm{QT}_{\mathrm{C}}$ interval were also recorded in all the victims of yellow scorpion stings [16] [17] [19].

The effects of autonomic stimulation usually mask those of electrolyte changes. It seems likely that vagal stimulation potentiates, while sympathetic stimulation masks the effect of electrolyte changes in the ECG recordings, since the changes were more rapid in onset and much more pronounced when the sympathetic actions of the venom were blocked [16] [17] [19].

\subsubsection{Hyperkalemia in Scorpion Envenoming}

1) Hyperkalemia could be due to cardiac sarcolemmal defects

Hyperkalemia could be seen by the tall, peaked, and slender T waves, and the wide QRS complex characteris- 
tic of Hyperkalemia. There was an increase in serum potassium levels in dogs after venom injection [24]. There is enough evidence to show that these animals also had cardiac sarcolemmal defects indicated by altered $\mathrm{Na}^{+}$$\mathrm{K}^{+}$ATPase, $\mathrm{Mg}^{++}$ATPase and $\mathrm{Ca}^{2+}$ ATPase activities and a reduction in $\mathrm{Na}^{+}-\mathrm{K}^{+}$ATPase activity of erythrocytes [21]. These results indicate that the cell membrane is leaking, and this could be the reason for hyperkalemia.

2) (II) Hyperkalemia is known to produce atrio-ventricular abnormalities and AV block, Junctional or ventricular rhythms and terminally ventricular fibrillation. Few of the venom treated animals had these types of ECG abnormalities. Amoreuxi venom caused a significant fall in serum potassium level 15 min after venom injection, returned to the pre-injection level $5 \mathrm{hr}$ after injection and became significantly higher than the pre-injection level at $7 \mathrm{hr}$ after injection [16].

\subsection{Electron-Microscopic Examination}

The changes consisted of degenerative muscle fibers, local necrosis and interstitial oedema. Although the changes were first ascribed to sympathetic over-stimulation and massive outpouring of catecholamines, careful electron-microscopic examination of the specimens showed

1) Intracellular oedema, dilatation of tubular system,

2) Scattered destruction of the I-band,

3) Lipid deposition and,

4) Absence of changes in mitochondria, nucleus or sarcolemma.

These changes indicated that "catecholamine over secretion" alone cannot explain the cardiovascular changes or the rapid cardiac failure seen in severe scorpion poisoning. Myocardial damage is probably produced through electrolyte upsets, although other metabolic, haemodynamic and myogenic factors may have a contributing role [14] [15] [52]-[54].

The most significant ECG changes appeared to be myocardial ischemia and either anterior or inferior wall infarction. In addition to elevation of serum cardiac enzymes, myocardial infarction was confirmed in several cases by post-mortem examination.

\subsection{Echocardiographic and Radionuclide Angiographic Observations}

The diversity of the cardiovascular manifestations of patients stung by scorpion is well known. Seven symptomatic children with scorpion envenomation were studied. The offending scorpion was yellow scorpion Leiurus quinquestiatus.

Abnormal echocardiograms on admission were observed in scorpion sting patients. Poorly contracting wall motion (global) with decreased systolic left ventricular performance and normal wall thickness was present in all three children. Pulse Doppler mitral incompetence was recorded in patients 2 and 3. The fractional percentage was lower than normal in two patients, borderline-low in the third patient [14] [15] [52]-[54].

\subsubsection{Echocardiographic Evidence of Myocardial Damage}

Echocardiographic examination performed in all the scorpion sting patients from 9 hours to 3 days after the scorpion sting (Tityus serrulatus) showed depressed left ventricular systolic function characterized by poor motion of the inter-ventricular septum or decreased motion of the left ventricular posterior wall shortening, or a combination of these. Color-flow Doppler mapping studies showed mitral regurgitation [5] [6].

\subsubsection{Pathogenesis of Depressed Left Ventricular Systolic Functions}

Pathogenesis of depressed left ventricular systolic function is not yet known. It could result from acute arterial hypertension or from myocardial damage due to an effect of massive catecholamine release or due to direct effect of the venom. Increased creatine kinase enzyme activity has been observed in patients with severe scorpionism who have electrocardiographic changes resembling an acute myocardial infarction-like pattern. These ECG changes or increased creatine kinase enzyme activity or both were also detected in the scorpion sting victims [5] [6].

Transient acute mitral regurgitation was observed in the scorpion sting victims. It may have resulted from impaired contraction of papillary muscles or from alterations of geometry and functional integrity of the mitral 
valve apparatus secondary to left ventricular dysfunction or both. The echocardiographic findings support the hypothesis that acute left ventricular failure is one of the pathogenic mechanisms of pulmonary oedema after scorpion envenomation [5] [6].

\subsection{Radionuclide Angiograms}

Poorly contracting left ventricle (hypokinetic global wall motion) with depressed systolic performance was seen in patients 1, 2 and 3 . The ejection fraction ranged from 19\% - 50\%. In patient 5 there was no correlation between the abnormal angiogram, the mild symptomatology and the normal echocardiogram [54].

\section{Acute Myocarditis and Cardiac Enzymes}

1) The cardiac enzymes are retained within the cells surrounded by metabolically active plasma membrane. A reduction in the oxygenated blood supply will promote deterioration of the membrane and leakage of the enzymes from damaged or dying cells into circulation. The leaked enzymes remain in the circulation until they are metabolically degraded. This could be the reason for an apparent and significant rise in the enzyme levels in envenoming, and for reversal of ECG and cardiac enzyme levels following the administration of Scorpion antivenom (SAV) to the envenomed animals [55] [56].

2) An increase in Succinate dehydrogenase and CPK activities was observed following Leiurus quinquestriatus envenoming. Envenoming by Androctonus amoreuxi resulted in an apparent, but not significant increase in SGOT, LDH, and G-6-P dehydrogenase levels, whereas SGOT, SGPT, LDH and CPK activities were normal in patients stung by the scorpion Hemiscorpius lepturus. A rise in SGPT and SGOT levels was reported with from the scorpion Buthus tamulus.

3) Sofer and Gueron reported high levels of SGOT, CPK, and CK-MB and suggested that these might account for the cardiovascular changes. The electrocardiographic, echocardiographic, radionuclide and ventriculography studies also showed an elevation of SGOT, CPK and CK-Mb ratio in scorpion sting victims [54] [55].

4) The transient elevation of SGOT levels sometimes raises practical difficulties in the diagnosis of myocardial damage, and normal levels do not exclude this diagnosis. The elevation of LDH levels, though also transient, persists much longer, but elevated LDH levels are not always seen after myocardial damage. The measurement of the activity of CK-MB is now widely used to detect and monitor myocardial damage. When ECG and necropsy studies are performed they can confirm or exclude myocardial damage. Alpha hydroxyl butyric dehydrogenase (alpha $\mathrm{HBDH}$ ) is found to be above normal due to myocardial damage.

5) Total LDH, SGOT, CK-MB, and alpha HBDH levels were increased following envenoming. SGOT and LDH activities were elevated in the experimental dogs after envenoming. Our results of an increase in LDH, $\mathrm{LDH}_{1}$ (specific for heart tissue) and the ratio of $\mathrm{LDH}_{1}$ to total $\mathrm{LDH}$ (more than 0.5) are suggestive of myocardial damage due to scorpion envenoming [53].

6) Serum creatine kinase (CK) measurement is established as a sensitive indicator of acute myocardial infarction. Serum CK activity is raised in muscle disease, brain damage or in pulmonary embolism. The specificity may be expected to be improved by serum CK isoenzyme determination, since the MB isoenzyme of CK is found almost exclusively in the myocardium.

7) The enzymatic activity of creatine kinase-MB isoenzyme (CK-MB) a sensitive and specific marker of myocardial damage is elevated in children stung by the scorpion Leiurus quinquestriatus from Israel. Many of these victims had enzymatic myocardial involvement characterized by high total CPK levels ranging between 277 and 3000 U/liter (normal: <100 U/liter), elevated CK-MB level and a CK-MB/CPK ratio exceeding 6\%. Many of these children had ECG changes consistent with myocardial damage. Additionally, elevated SGOT levels were observed [52] [53] [57] [58].

\section{Conclusions on Presence of Cardiac Enzymes in Scorpion Envenoming Syndrome}

Scorpion envenoming syndrome results in a significant elevation of LDH, SGOT, CK-MB and alpha HBDH enzyme levels associated with changes in the ECG. Scorpion envenoming is a rural emergency occurring mainly in developing countries where the facilities to monitor and treat scorpion sting victims in intensive care units are scarce. The monitoring of either LDH or SGOT enzyme levels supported by ECG recording under such circumstances may prove to be helpful [56]. 


\section{Acute Myocarditis and Autonomic Storm}

The mechanism of action of scorpion venom/toxins on the toxicological effects of scorpion envenoming syndrome, the significance of an elevation of counter-regulatory hormones-suppressed insulin secretion-hyperglycemia-sudden increase in Free Fatty Acids-cardiac sarcolemmal defects, reversal of all these effects by insulin administration, are reviewed (Figure 1).

\subsection{What Is the Cause of Death in Scorpion Envenoming Syndrome?}

Scorpion envenoming syndrome causes autonomic storm resulting in acute myocarditis, initial transient hypertension, hypotension, cardiovascular disturbances, acute pancreatitis, disseminated intravascular coagulation (DIC), Adult respiratory distress syndrome (ARDS), and many other clinical manifestations. All these manifestations could be due to alterations in the hormonal mileu-suppressed insulin secretions-hyperglycemia, lipolysis and sudden increase in free fatty acid levels and death (Figure 1).

\subsection{Scorpion Envenoming Syndrome Causes an Autonomic Storm Releasing Massive Quantities of Counter-Regulatory Hormones}

Scorpion toxins target $\mathrm{Na}^{+}, \mathrm{K}^{+}, \mathrm{Ca}^{2+}$, and $\mathrm{Cl}^{-}$channels causing direct effects and the release of neurotransmitters such as acetylcholine and catecholamines (51). Scorpion envenoming syndrome causes an autonomic storm releasing massive quantities of counter-regulatory hormones.

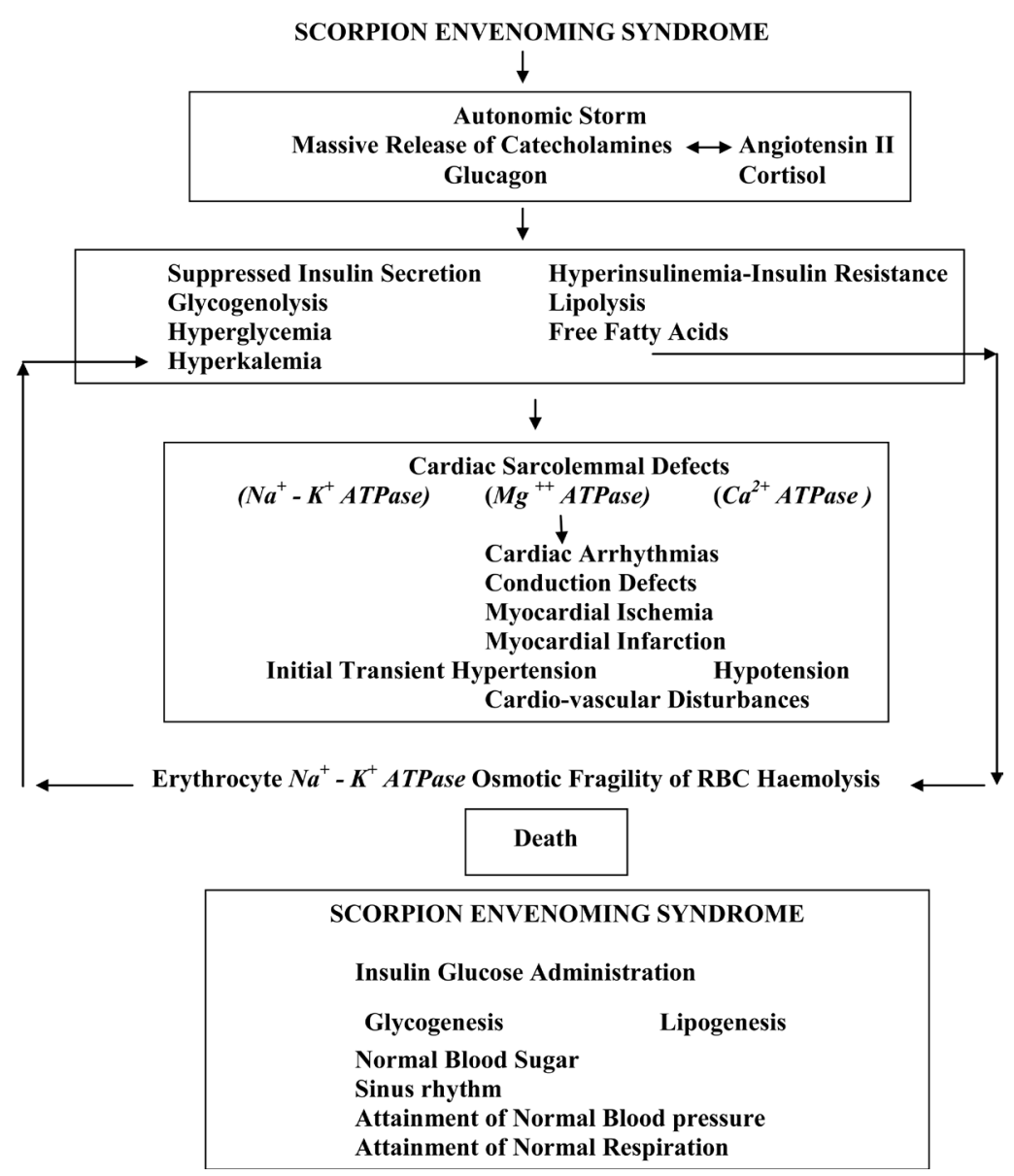

Figure 1. Mechanism of cardiac sarcolemmal defects — cardiac arrhythmias, ischemia \& infarction and death in scorpion envenoming syndrome also shows administration of insulin-glucose reversing metabolic, cardio-vascular \& ECG changes resulting in sinus rhythm, attainment of normal blood pressure. 
The following counter-regulatory hormones are released:

1) adrenaline,

2) nor-adrenaline [5] [6] [13]-[19],

3) angiotensin II [15] [28],

4) reduced insulin [22] [25] [59] [60],

5) glucagon [23] [59] [60],

6) glucocorticoids [22],

7) suppressed Insulin secretion [21] [22] [24] [29] [30] or

8) hyper-insulinemia (insulin resistance) [21] [22] [24] [29] [30]

9) renin [15].

The metabolic actions of these counter regulatory hormones result in lipolysis and a sudden increase in Free Fatty Acid levels (FFA) [21] [22] [24] [29] [30], glycogenolysis and a sudden increase in blood sugar levels-hyperglycemia [21] [22] [24] [29] [30], and result in death either singly or in combination.

\subsection{Actions of the Counter-Regulatory Hormones in Scorpion Envenoming Syndrome}

The counter-regulatory hormone secretions cause acute myocarditis [1]-[4] [9] [10] [14]-[17] [19] [21]-[37], cardiac sarcolemmal defects [20] [21], electrocardiographic changes, hemodynamic and cardiovascular changes, cardiogenic \& non-cardiogenic pulmonary oedema [30] [37], Adult Respiratory Distress Syndrome (ARDS) [34] [37], acute pancreatitis [11] [32], increased osmotic fragility of erythrocytes [26] [31] [35], Disseminated Intravascular Coagulation (DIC) [38] [39], Multi System Organ Failure (MSOF) either singly or in combination and death.

\subsection{Scorpion Envenoming-Autonomic Storm-Angiotensin II}

Scorpion envenoming results in an autonomic storm [1]-[5] [13] [14] [19] which leads to a massive release of catecholamines, suppressed insulin secretions (18) and an increase in angiotensin II levels [15] [28]. Angiotensin II stimulates the release of catecholamines, thereby synergizing and amplifying each other's actions, and these may act at least in part, at similar sites [42].

Initial transient hypertension followed by hypotension in scorpion envenoming could be due to massive release of catecholamines and Angiotensin II.

\subsection{Severe Scorpion Envenoming Causes an Increase in the Circulating Levels of Blood Sugar, Insulin, Glucagon, and Cortisol}

Severe scorpion envenoming causes an increase in the circulating levels of blood sugar, suppressed insulin secretion, glucagon, and cortisol [22]-[25] [33].

Subcutaneous (s.c.) injection of scorpion (Mesobuthus tamulus Concanesis, Pocock) venom either $2 \mathrm{mg} / \mathrm{kg}$ or $3 \mathrm{mg} / \mathrm{kg}$ or $4 \mathrm{mg} / \mathrm{Kg}$ (body weight) either in the rabbits or dogs resulted in depletion of glycogen content of atria, ventricle (cardiac muscle), liver and skeletal muscles [9] [10] [23] [30] [31] [33].

Subcutaneous (s.c.) injection (3 mg/kg) or I.V. (4 mg/Kg) injection of scorpion venom (Mesobuthus tamulus Concanesis, Pocock) in the dogs caused hypo-insulin secretion [17]-[19] [22] 30 min after venom injection, and elevated insulin levels [17]-[19] [22] 60 min after venom injection. Insulin and blood glucose were higher after 60 and 120 min of venom injection.

\subsection{Nor-Epinephrine Released from the Adrenergic Nerve Terminals of the Pancreas May Be a More Effective Stimulus to Glucagon Secretion}

Leiurus quinquestriatus scorpion venom in the rat pancreatic islets inhibited insulin secretion and stimulation of glucagon secretion. Nor-epinephrine released from the adrenergic nerve terminals of the pancreas may be a more effective stimulus to glucagon secretion than nor-epinephrine reaching the pancreas through the general circulation [59] [60].

\subsection{Release of Increased Glucocorticoids Secretion}

Glucocorticoids could also be released following stress or injury. The "sympatho-adrenal axis" primarily serves 
to maintain the pressure necessary for organ perfusion. During the "ebb phase", the insulin levels are reduced and with the onset of hyper-metabolism, characteristic of the "flow phase", the hormonal environment is changed and the insulin levels are increased [61].

\subsection{The Effects of the Hormonal Actions Are Synergistic in the Presence of Increased Circulating Levels of All the Catabolic Counter-Regulatory Hormones}

In the presence of increased circulating levels of all these catabolic counter-regulatory hormones, the effects of these hormonal actions are synergistic and sustained hepatic glucose production is observed [61] [62]. The simultaneous elaboration of the counter-regulatory hormones is partly responsible for the pathogenesis of a variety of clinical and biochemical manifestations following scorpion envenoming. This could be the reason for glycogenolysis in the atria, ventricles, and liver; and skeletal muscles [9] [10], hyperglycemia [18] [19] [22]-[28] [30]-[37]; lipolysis and elevated free fatty acid levels [18] [19] [22]-[28] [30]-[37], increased protein breakdown products [18] [19] under the catabolic influence of the counter-regulatory hormones, and a simultaneous suppressed insulin secretion, or insulin resistance [22] [25] [33] [34] [36] [37].

\section{Acute Myocarditis-Sudden Increase in Free Fatty Acids}

Massive release of catecholamines, release of Angiotensin II, increased glucagon, increased glucocorticoids, either hypo-insulin secretion or hyper-insulinemia (insulin resistance) thus produced can activate the hormone sensitive lipase, promote free fatty acid mobilization and produce a sudden increase in free fatty acid levels after venom injection [23] [25] [26] [30] [33] [39] [41].

\subsection{Severe Scorpion Envenoming Is a Syndrome of Fuel-Energy Deficits \& Result in Multi-System-Organ-Failure (MSOF)}

Severe scorpion envenoming is thus a syndrome of fuel-energy deficits and an inability of the vital organs to utilize the existing metabolic substrates. This ultimately may result in Multi-System-Organ-Failure (MSOF) and death. These changes are brought about by a massive release of catecholamines, angiotensin II, glucagon, glucocorticoids, and either insulin deficiency or insulin resistance.

\subsection{Physiological Basis of the Glycogenolysis-Hyperglycemia in Scorpion Envenoming}

\subsubsection{Role of Glucagon}

Glucagon acts mostly on the liver and adipose tissue where it antagonizes the action of insulin. Glucagon raises blood glucose concentration by enhancing the breakdown of liver glycogen to glucose (glycogenolysis) and by promoting gluconeogenesis from lactate, pyruvate, glycerol and amino acids.

Glycogenolysis produces a rapid rise in blood glucose within a few minutes [40] [41]. This could be the reason for glycogenolysis in the cardiac muscle, skeletal muscle and liver tissue after scorpion envenoming [9] [10] [23] [30] [31] [33] [39]. Gluconeogenesis produces a slower, more sustained rise in blood glucose lasting for hours or days [40] [41].

\subsubsection{Glucagon Is Potent as a Stimulant of Glucose Output from the Liver}

Glucagon as a stimulant of glucose output from the liver is, on a molar basis, more potent than insulin as a promoter of glucose retention [40] [41].

\subsubsection{Role of Catecholamines}

Catecholamines (Adrenaline and Nor-adrenaline) act similarly (like glucagon) to enhance glycogenolysis but on molar basis, Adrenaline and Nor-adrenaline, are weaker than glucagon; however, Nor-adrenaline released locally at sympathetic nerve terminals might have powerful effects.

Catecholamines (Adrenaline and Nor-adrenaline) antagonize the actions of insulin by increasing c AMP formation in the liver, fat and muscle; in the liver it activates Phosphorylase, promotes glycogenolysis, and leads to hyperglycemia [40]-[42].

Catecholamines promote glycogenolysis, in muscle and enhance lactate formation. 


\subsubsection{Adrenalin Inhibits Glucose-Induced Secretion of Insulin}

Adrenalin enhances gluconeogenesis from lactate. Adrenalin inhibits glucose-induced secretion of insulin from the beta cells of islets in endocrine pancreas. Sudden stoppage of insulin secretion leads rapidly to hyperglycemia [40]-[42].

The acute hyperglycemia seen in acute myocarditis [8]-[10] [21]-[25] [27] [30] [33]-[37] induced by injection of scorpion venom (Buthus tamulus) could be because of suppression of insulin release from beta cells of the pancreas as well as the capacity for adrenal catecholamines to provoke glycogen breakdown and peripheral inhibition of glucose uptake [32] [37].

\subsubsection{Reduction in Glycogen Content}

Epinephrine stimulates inhibition of insulin secretion which in turn stimulates glycogenolysis in the muscle, thus providing a substrate in the form of lactate for hepatic gluconeogenesis [30]. This might explain the reduction in glycogen content of atria, ventricle, liver and skeletal muscle in rabbits after venom injection and hyperglycemia in the dogs 30 min after venom injection [9] [10] [14] [19]-[24] [26] [27].

\subsection{Significance of Sudden Increase in Serum Free Fatty Acids}

\subsubsection{Presence of the Un-Oxidizable Free Fatty Acids Could Be Toxic}

The catecholamines make available for active tissues more oxidizable substrates and at the same time depress the oxidation of glucose. There may be an excess of free fatty acids in the ischemic myocardium especially at the time when sudden death from arrhythmias are known to be common [62] [63] and the presence of these un-oxidizable free fatty acids could be toxic [41].

\subsubsection{Role of Glucagon}

Glucagon is a powerful lipolytic agent, acting via c AMP to phosphorylate a lipase in adipose tissue which releases FFA and glycerol in to circulation [23] [41] [59] [60].

\subsubsection{Role of Adrenalin and Nor-Adrenalin}

Adrenalin and noradrenalin activate specific lipase in adipose tissue and muscle which breaks down triglycerides to FFA and glycerol. This lipolysis might be mediated by cyclic AMP. This action is antagonized by insulin.

\subsubsection{Lipolytic Action of Adrenaline Is Brief and the Action of Noradrenalin Is Prolonged}

The catecholamines make available for active tissue more oxidizable structures, such as FFA, glycerol, and ketone bodies, and at the same time depress the oxidation of glucose. The lipolytic action of adrenaline is brief and the action of noradrenalin is prolonged. The catecholamines promote lipolysis in adipose tissue and proteolysis in muscle [41].

\subsection{Effect of Increased Free Fatty Acids on the Heart}

\subsubsection{Increased Oxygen Consumption}

The use of increased amounts of Free Fatty Acids results in increased oxygen consumption. This could aggravate the ischemic injury to myocardium, predisposing to arrhythmias and heart failure.

\subsubsection{Free Fatty Acids Increase the Susceptibility of the Ventricles to the Disorganized Electrical Behavior}

The elevated free fatty acids also increase the susceptibility of the ventricles to the disorganized electrical behavior and produce ectopic beats in the vulnerable period of cardiac cycle [63].

\subsubsection{Free Fatty Acids Inhibit Cardiac Sarcolemmal $\mathrm{Na}^{+}-\mathrm{K}^{+}$ATPase Activity}

High levels of free fatty acids produce inhibition of $\mathrm{Na}^{+}-\mathrm{K}^{+}$ATPase activity [64] [65] and produce cardiac sarcolemmal defects. Alterations in cardiac sarcolemmal $\mathrm{Na}^{+}-\mathrm{K}^{+}$ATPase, $\mathrm{Mg}^{++}$ATPase and $\mathrm{Ca}^{2+}$ ATPase activities indicate cardiac sarcolemmal defects [21]. 


\subsubsection{Free Fatty Acids Increase the Tendency to Intravascular Thrombus}

The increased Free Fatty Acids, by altering the functions of platelets, may increase the tendency to intravascular thrombus and result in disseminated intravascular coagulation [38] [39] [63].

\subsubsection{Free Fatty Acids Increase Myocardial Damage}

Scorpion stings can be accompanied by enzymatic and electrocardiographic evidence of myocardial damage. Examination of myocardial ultra structure following scorpion sting reveals various types of cellular damage. Echocardiographic and radionuclide studies in human victims have shown depressed L.V. systolic function in patients tested within a few hours of scorpion sting.

\subsection{The Metabolism of Normal Myocardium and the Role of Insulin}

Under normal conditions, the myocardium derives its energy from the aerobic metabolism of substrates extracted from the plasma. The most important fuels are Free Fatty Acids (FFA), glucose, triglycerides, amino acids, Pyruvate and lactate. At rest, the myocardial extraction of many of these substrates is generally related to their arterial concentrations, but the relative uptake of each compound may be modified by hormones and utilization of other substrates. Thus, glucose transport into the myocardial cell depends on insulin, and increases of plasma insulin concentration enhance the extraction of glucose by the heart.

\subsubsection{The Metabolism of Injured Myocardium and the Role of Insulin}

High plasma FFA concentrations inhibit glucose uptake by the heart. In the human heart, a $10 \%$ increase of plasma FFA decreases the myocardial extraction of glucose by $17 \%$, while a $10 \%$ increase of plasma insulin enhances glucose utilization by an average of $24 \%$. We have consistently demonstrated a sudden increase in FFA levels (200\% to 300\%) in the experimental scorpion envenoming [23] [25] [27] [30] [31] [33] [53] [62] [64] [66].

\subsubsection{The Metabolism of Injured Myocardium}

High plasma FFA concentration increases myocardial oxygen consumption without augmenting mechanical performance [62]-[64] [66].

\subsubsection{Effects of Acute Ischemia on Myocardial Metabolism}

1) The immediate metabolic changes in the myocardium during acute ischemia are largely determined by the rates of glycolysis and glycogenolysis and to a lesser extent, of fatty acid availability in relation to the demand for phosphorylation [23] [25] [27] [30] [31] [33] [39] [62]-[64] [66].

2) Glycolysis increases with mild hypoxia, and in areas of profound hypoxia, decreased glycogenolysis occurs. Hydrolysis of stored triglycerides results from the activation of myocardial lipase with increases in FFA. Greater glycogenolysis was observed in atria and ventricular tissue in response to a smaller dose of scorpion venom compared to lower rate of glycogenolysis with a higher dose of scorpion venom [9] [10].

\subsection{Myocardial Vulnerability}

While myocardial vulnerability may finally be determined by critical extra and intra cellular gradients in the availability of $\mathrm{Ca}^{2+}, \mathrm{Mg}^{++}$and $\mathrm{K}^{+}$, the intracellular concentrations of these ions, are in turn, dependent on factors which influence their transference across the cell and mitochondrial membranes. A decreased availability of $\mathrm{Ca}^{2+}$ can interfere with Actin-Myosin coupling so that contractility is impaired. We have demonstrated hypocalcemia [38] [39].

An excess of $\mathrm{K}^{+}$could alter the action potential so that self perpetuating re-entry currents are established [67]. Low concentrations of myocardial $\mathrm{Mg}^{++}$are associated with arrhythmias and sudden death [68]-[73].

\subsection{Accumulation of Excess Intra Cellular FFA: Detergent Effect on Cell Membranes}

Accumulation of excess intra cellular FFA could have a detergent effect on cell membranes [64] [65]. This accumulation could result from decreased oxidation in the myocardium and catecholamine-induced hydrolysis of stored triglycerides in addition to increased uptake resulting from higher concentrations in arterial blood. Ele- 
vated concentrations of plasma FFA have been associated with an increased prevalence of serious ventricular arrhythmias and death in man and in dogs. Elevated FFA levels have also been shown to increase myocardial oxygen consumption and, when there is an under-perfusion of the left ventricle, to decrease myocardial contractility. High plasma FFA levels increased ST elevation in the ECG and plasma CK enzyme levels, suggesting that they may lead to more extensive damage [14]-[19] [34]-[37].

\subsection{Excess Un-Oxidized FFA Probably Become Toxic to the Myocardium}

Excess un-oxidized FFA probably becomes toxic to the myocardium only when there is acute ischemia. It is difficult to dissociate the toxic effects of increased local FFA concentrations from those of catecholamines, although it is possible to experimentally show that elevations of plasma concentrations of FFA can lead to adverse effects on myocardial function in the absence of changes in the catecholamine levels.

\subsection{Interfere with Tropomyosin-Troponin Activation of Actin-Myosin Coupling}

The biochemical consequences which result from the intra cellular accumulation of excess un-oxidized FFA for $\mathrm{Ca}^{2+}$ will occur simultaneously with protein binding, possibly making less ionic calcium available for passage into the sarcotubular reticulum. This might interfere with tropomyosin-troponin activation of Actin-Myosin coupling [67].

\subsection{Intra Cellular Depletion of $\mathrm{Mg}^{++}$Would Be Exaggerated}

Magnesium-fatty acid complexes could result in intra cellular depletion of $\mathrm{Mg}^{++}$and depletion of $\mathrm{Mg}^{++}$would be exaggerated. This might lead to uncoupling of oxidative phosphorylation, possibly by interfering with a Magnesium-dependent ATPase system $\left(\mathrm{Mg}^{++}\right.$ATPase) [20] [21] [67]. Cardiac sarcolemmal $\mathrm{Na}^{+}-\mathrm{K}^{+}$ATPase and erythrocyte $\mathrm{Na}^{+}-\mathrm{K}^{+}$ATPase are also a Magnesium-dependent ATPase system [20] [21] [31] [68]-[75].

\subsection{Excess Un-Oxidized Fatty Acids or Metabolites Could Alter the Stabilization of Lysosomal Membranes}

Fatty acids may be transported intra-cellularly in the un-esterfied form and have specific affinities for certain subcellular structures. Esterification of certain phospholipids of the mitochondrial and cell membranes may be altered when there is excess un-oxidized FFA. Different cell membranes have lipoprotein layers with variable permeability for ions, and this could also be changed if the intra cellular accumulation of FFA were to have a detergent action leading to cat-ion loss. Excess un-oxidized fatty acids or metabolites could alter the stabilization of lysosomal membranes and mitochondrial integrity, and together they can have a synergistic effect [62] [67] [76].

\subsection{Insulin Levels in Scorpion Envenoming}

Insulin levels, as measured by radioimmunoassay, were significantly suppressed or elevated after venom injection [22] [23] [30] [33].

Insulin/glucagon (I/G) ratio.

\subsubsection{Catabolic State with Low Insulin/Glucagon (I/G) Ratio}

The insulin/glucagon ratio (I/G ratio) may be more important than the levels of individual hormones. When I/G ratio are low, a catabolic state is produced in which nutrients are mobilized. Scorpion envenoming causes a low I/G ratio [23] [25].

\subsubsection{Hyperglycemia and Hyper-Insulinemia-Insulin Resistance}

Hyperglycemia and hyper-insulinemia-insulin resistance is observed in all our experimental animals [22] [24][28] [30]-[33] and in the studies reported by Prem Kumar Choudhary \& Deshpande [77]. Thus, development of insulin resistance is a possibility in scorpion envenoming syndrome.

\subsubsection{Raised Haematocrit Levels-Hyperinsulinemia-Insulin Resistance}

There is limited evidence that raised Haematocrit levels may be associated with insulin resistance. We have ob- 
served an increase in Haematocrit following venom injection [24].

\subsubsection{Mechanisms That Can Produce Hyper-Insulinemia and Hyperglycemia in Scorpion Envenoming Syndrome}

We have observed hyperglycemia along with reduced insulin secretion and hyperglycemia along with hyperinsulinemia in our experimental animals [21]-[28] [30]-[32]. This was confirmed by Deshpande and his coworkers in their experimental animals [77].

1) Insulin Receptor and the Signaling Pathways Not Defective

Ability of exogenous insulin administration to reverse hemodynamic, cardiovascular, metabolic, electro-cardio graphic (ECG) changes, pulmonary oedema and many other clinical manifestations in the experimental animals and in the scorpion sting victims, suggests that the insulin receptor and the signaling pathways are not defective [30] [33] [34] [36] [37].

\section{2) Counter-Regulatory Hormones-Hyperglycemia-Failure of Internally Secreted Insulin}

The magnitude of increased insulin levels is perplexing and indicates the failure of insulin action. We are measuring insulin using immunological techniques; the action of functionally active insulin cannot be ascertained. Hyperglycemia is observed in the experimental animals and in scorpion sting victims [11]-[13] [15]-[19] [22]-[25] [27] [28] [30] [32] [33]. It is possible that the insulin assayed is not functionally active [77]. In such a situation, it is hypothesized that the insulin molecule after venom injection is not a normal functional molecule.

3) Some Cytokines Are Toxic to Beta Cells of Endocrine Pancreas

Insulin is secreted as pre-pro-hormone. Beta cells are reported to the toxic effects of some cytokines such as tumor necrosis factor-a, interferon-y, interleukin. Buthus tamulus venom is shown to increase the cytokines level and its toxic effect on beta cells to provide defective/abnormal insulin molecule [78].

\section{Causes of insulin resistance}

In any insulin-resistant state, the cause of insulin resistance can be due to an abnormal beta cell secretory product, circulating insulin antagonists, or target tissue defect in insulin action [62] [63] [76].

\section{4) Insulin Resistance-Pre-Receptor, Receptor, and Post-Receptor Abnormalities}

Insulin resistance may occur because of pre-receptor, receptor, and post-receptor abnormalities. Insulin resistance as a result of pre-receptor involves metabolic (elevated counter-regulatory hormonal and non-hormonal) factors. Circulating insulin antagonists as a cause of insulin resistance have been clearly demonstrated in a variety of clinical syndromes. Excess endogenous glucocorticoids are often associated with carbohydrate intolerance. Availability of substrates and plasma levels of glucagon, glucocorticoids stimulate hepatic glucose production through increased activity of hepatic gluconeogenic enzymes [42] [62] [65]-[67].

5) Post-Receptor Resistance-Hormonal Antagonists

Hormonal antagonists consist of all counter-regulatory hormones

Post-receptor resistance can be caused by other hormones. Hormonal antagonists consist of all counter-regulatory hormones (growth hormone, Cortisol, glucagon, and epinephrine). Scorpion envenoming increased these hormones [23].

6) Catecholaminergic Hyperactivity Antagonize Insulin Effects

States of Catecholaminergic hyperactivity antagonize insulin effects through several mechanisms. Catecholamines stimulate hepatic glucose production by direct stimulation of glycogenolysis and gluconeogenesis and indirectly by increasing glucagon secretion. Additionally, catecholamines decrease peripheral glucose disposal both in vitro and in vivo catecholaminergic hyperactivity [42] [62] [63] [65]-[67].

7) Effect of Acidic pH to Accelerate Insulin Dissociation from the Receptor

The accelerated receptor degradation has been found to be responsible for a decreased number of receptors. The effect of acidic $\mathrm{pH}$ to accelerate insulin dissociation from the receptor is markedly reduced, leading to an inhibition of receptor recycling and acceleration of receptor degradation. An increase in $\mathrm{pH}$ (acidosis) has been demonstrated in the experimental scorpion envenoming [30].

\section{Acute Myocarditis-Cardiac Sarcolemma}

Cardiac sarcolemma is a dynamic structure. Cardiac sarcolemma plays an important role in maintaining appropriate intracellular levels of sodium, potassium, magnesium, calcium ions and thereby participates in contraction and relaxation of the myocardium [68]-[71]. Mechanical properties of cardiac muscle, being dependent on dis- 
tribution and movements of ions across sarcolemma are likely to be influenced by sarcolemmal ATPase activities. This is by virtue of the presence of $\mathrm{Na}^{+}-\mathrm{K}^{+}$ATPase, $\mathrm{Mg}^{++}$ATPase, and $\mathrm{Ca}^{2+}$ ATPase enzymes located on the sarcolemmal membrane [20] [21] [72]. Suppressed insulin secretion [22] [25] or hyper-insulinemia (Insulin resistance) [16]-[18] [22] [24] [25] [28] [30] [31] could result in inhibition of $\mathrm{Na}^{+}-\mathrm{K}^{+}$ATPase enzyme activities and stimulation of $\mathrm{Ca}^{2+}$ ATPase enzyme activities. Cardiac sarcolemmal defects could also result in changes in myocardial contractility—cardiac failure and death in scorpion envenoming syndrome [20] [21].

The physiological basis of the role of cardiac sarcolemmal $\mathrm{Na}^{+}-\mathrm{K}^{+}$ATPase, $\mathrm{Mg}^{++}$ATPase, and $\mathrm{Ca}^{2+}$ ATPase enzymes, cardiac sarcolemmal defects in acute myocarditis, its implications in scorpion envenoming syndrome [20] [21], and their reversal with Insulin-Glucose Administration (in the experimental animals and scorpion sting victims) [30]-[33] are reviewed.

Based on our animal experiments in which insulin administration reversed the metabolic and ECG changes induced by scorpion envenoming and treating the poisonous scorpion sting victims with insulin, we consider that insulin has a primary metabolic role in preventing, counter-acting and reversing all the deleterious effects of FFA by inhibiting the catecholamine induced lipolysis, and $\mathrm{K}^{+}$[30] [33] [37].

Scorpion venom increases the membrane permeability to $\mathrm{Na}^{+}$by opening the voltage sensitive $\mathrm{Na}^{+}$channels. This effect is associated with $\mathrm{Ca}^{2+}$ entry blockade of $\mathrm{Ca}^{2+}$-activated $\mathrm{K}^{+}$channels in which there is a disturbance of transmembrane $\mathrm{K}^{+}$gradient resulting in either absolute or relative hyperkalemia [16]-[19].

\subsection{Factors That May Contribute and Aggravate the Condition of Hyperkalemia}

Following factors may contribute and aggravate the condition of hyperkalemia:

1) The deficiency of some of the normal body mechanisms causing $\mathrm{K}^{+}$influx and arising primarily from the pronounced prolonged hyperglycemia, enhanced glycogenolysis [9] [10] [25] [26] [30] [33] and inhibited glycogenesis from decreased insulin secretion [16]-[19] [22] [25] [26] [33];

2) Venom induced release of catecholamines [5] [6] [13]-[19], which in turn cause $\mathrm{K}^{+}$efflux from the liver;

3) Decreased serum $\mathrm{Ca}^{2+}$ secondary to its increased deposition in the heart and/or decreased intestinal absorption and increased urinary excretion [5] [6] [13]-[19],

4) Decreased serum magnesium [13]-[19],

5) Acute insulin deficiency [16]-[19] [21] [26] [30] [33],

6) Inhibition of cardiac sarcolemmal $\mathrm{Na}^{+}-\mathrm{K}^{+}$ATPase activities [21],

7) Inhibition of erythrocyte $\mathrm{Na}^{+}-\mathrm{K}^{+}$ATPase activities [31].

The unopposed hyperkalemia (together with the hypocalcemia and hypomagnesaemia) can explain the electrocardiographic (ECG) changes seen in both the sting victims [5]-[7] [11] [12] [14]-[16] [19] [34] [37] [52]-[54] [57] [58] and experimental animals injected with scorpion venom [7]-[10] [13] [22] [36].

\subsection{Role of the $\mathrm{Na}^{+}-\mathrm{K}^{+}$ATPase Activity in Excitation Leading to the Contraction of the Cardiac Muscle}

$\mathrm{Na}^{+}-\mathrm{K}^{+}$ATPase is $\mathrm{Mg}^{++}$dependent and is involved in the transport of $\mathrm{Na}^{+}$and $\mathrm{K}^{+}$and Magnesium is necessary for the action of ATPase. Without its optimal activity, the cells lose the capacity to maintain an appropriate concentration gradient across the cell membranes. The main role of the $\mathrm{Na}^{+}-\mathrm{K}^{+}$ATPase is the active cat-ion exchange transport. Three sodium ions from inside to outside the cell and two potassium ions from outside to inside the cell move by hydrolysis of one ATP. Reciprocal dependence of transport is complete i.e. either the presence of external potassium or the absence of internal sodium stops the active transport of both ions. The active transport results in completing the preparation for excitation. The decrease in ATP and the increase in iP and ADP affect the energy metabolism. The activity is controlled by various factors like the concentration of the substrate (ATP) together with the products (ADP and inorganic phosphate) and the accelerators $\left(\mathrm{Mg}^{++}, \mathrm{Na}^{+}\right.$and $\mathrm{K}^{+}$). In this case, position (whether outside or inside the cell) is crucial.

The $\mathrm{Na}^{+}-\mathrm{K}^{+}$ATPase plays an important role in excitation leading to the contraction of the cardiac muscle. Depending upon whether the enzyme is inhibited or stimulated and so varying the different ionic concentrations inside and outside the cell, the enzyme is able to alter the cardiac contractility [68]-[72] [74]-[76] [79]-[81].

\subsection{Cardiac Sarcolemma-Participates in Contraction and Relaxation of the Myocardium}

Heart sarcolemma is a dynamic structure. Cardiac sarcolemma plays an important role in maintaining appropri- 
ate intracellular levels of sodium, potassium, magnesium, and calcium ions $\left(\mathrm{Mg}^{++}, \mathrm{Na}^{+}, \mathrm{K}^{+}\right.$, and $\left.\mathrm{Ca}^{2+}\right)$ and thereby participates in contraction and relaxation of the myocardium. This is by virtue of the presence of $\mathrm{Na}^{+}-\mathrm{K}^{+}$ ATPase, $\mathrm{Mg}^{++}$ATPase, and $\mathrm{CA}^{2+}$ ATPase enzymes located on the sarcolemmal membrane. By virtue of its complex structure and enzymatic characteristics, it is able to control the passage of substrates and ions into and out of the cell. It is possible that, in terms of evolution, one of the earliest functions of the cell membrane was the maintenance of appropriate intracellular concentrations of sodium and potassium ions. Adenosine Triphosphate (ATP) is required for this transport [68]-[72] [74]-[81].

Activation of $\mathrm{Na}^{+}-\mathrm{K}^{+}$ATPase is dependent upon a definite ratio of $\mathrm{Na}^{+}$inside and $\mathrm{K}^{+}$outside the cell [79]-[81]. Scorpion envenoming caused a significant decrease in $\mathrm{Na}^{+}-\mathrm{K}^{+}$ATPase activity in ventricular tissue from $4 \mathrm{mg} / \mathrm{kg}$ scorpion venom treated animals, and a mild fall in the enzyme activity from atria and ventricles in rabbits treated with $2 \mathrm{mg} / \mathrm{kg}$ scorpion venom treated animals [21]. Reduction in $\mathrm{Na}^{+}-\mathrm{K}^{+}$ATPase activity may result in increased intracellular sodium and extra-cellular potassium-hyperkalemia [24], and a loss of intracellular potassium.

\subsection{The Function of Sarcolemmal $\mathrm{Mg}^{++}$ATPase}

The magnesium plays an important role in the mitochondrial structure and in the activity of $\mathrm{Na}^{+}-\mathrm{K}^{+}$ATPase. The efficacy of magnesium in preventing and reversing early changes to mitochondria by a variety of challenges provides a clue to the efficacy of magnesium salts against a number of diverse cardio-toxic agents. Heart mitochondria are more susceptible than are of liver and kidney mitochondria to the impairment of oxidative phosphorylation caused by Magnesium deficiency. $\mathrm{Mg}^{++}$is necessary for the formation of compact $\mathrm{Mg}^{++}$ATP complex.

The function of sarcolemmal $\mathrm{Mg}^{++}$ATPase is unknown. It is suggested that $\mathrm{Mg}^{++}$ATPase generates the energy required for maintenance of ionic gradients across the cell membrane. It is also suggested that $\mathrm{Mg}^{++} \mathrm{AT}^{-}$ Pase maintains intracellular $\mathrm{Mg}^{++}$. There are reports to suggest that reduced $\mathrm{Mg}^{++}$results in cellular loss of potassium and gain in $\mathrm{Na}^{+}$resulting in reduction in the force of contraction. Thus, $\mathrm{Mg}^{++}$dependent loss of cellular potassium may result in a reduction in $\mathrm{Na}^{+}-\mathrm{K}^{+}$ATPase activity for which $\mathrm{Mg}^{++}$ATP is the substrate. Therefore, the associated alterations in the $\mathrm{Na}^{+}-\mathrm{K}^{+}$ATPase activities in atria and ventricles in 2 and $4 \mathrm{mg} / \mathrm{kg}$ scorpion venom treated experimental rabbits may be a reflection of altered $\mathrm{Mg}^{++}$ATPase activity [21]. Depressed $\mathrm{Na}^{+}-\mathrm{K}^{+}$ ATPase activity without any change in $\mathrm{Mg}^{++}$ATPase activity was demonstrated in left ventricular hypertrophy and failure in rabbits with aortic constriction [20] [68]-[75].

\subsection{The Atrial Sarcolemmal ATPase Activities}

The atrial sarcolemmal ATPase activities in the experimental animals treated with 2 and $4 \mathrm{mg} / \mathrm{kg}$ venom were similar. $\mathrm{Na}^{+}-\mathrm{K}^{+}$ATPase, $\mathrm{Mg}^{++}$ATPase and $\mathrm{Ca}^{2+}$ ATPase activities were reduced, and a significant reduction in $\mathrm{Ca}^{2+}$ ATPase activity was seen in the experimental animals [20] [21].

\subsection{Differences between Atrial and Ventricular Myocardial Cells}

Several anatomical and physiological differences exist between atrial and ventricular myocardial cells. Atrial cells are small, have neither $T$ tubules nor membrane triads, and generate less contractile force than ventricular muscle. The atria display greater mitochondrial $\mathrm{Ca}^{2+}$ transport than the ventricles, whereas $\mathrm{Ca}^{2+}$ transport in sarcoplasmic reticulum, which is relatively low in atrial muscle, is reported to be similar in atria and ventricles [68]-[75].

\subsection{Role of $\mathrm{Na}^{+}-\mathrm{K}^{+}$ATPase, $\mathrm{Mg}^{++}$ATPase and $\mathrm{Ca}^{2+}$ ATPase Activities}

\subsubsection{Role of $\mathrm{Na}^{+}-\mathrm{K}^{+}$ATPase Activity}

$\mathrm{Na}^{+} \mathrm{K}^{+}$ATPase is $\mathrm{Mg}^{++}$dependent and is involved in the transport of $\mathrm{Na}^{+}$and $\mathrm{K}^{+} . \mathrm{Mg}^{++}$is necessary for the action of $\mathrm{Na}^{+} \mathrm{K}^{+}$ATPase activity. Without the optimal $\mathrm{Na}^{+} \mathrm{K}^{+}$ATPase activity, the cells lose the capacity to maintain an appropriate concentration gradient across the cell membranes [68]-[75].

Inhibition of erythrocyte $\mathrm{Na}^{+} \mathrm{K}^{+}$ATPase was also observed in the experimental animals after envenoming. Inhibition of erythrocyte $\mathrm{Na}^{+} \mathrm{K}^{+}$ATPase was also observed in a scorpion sting victim [31]. 


\subsection{2. $\mathrm{Mg}^{++}$ATPase Activities}

Mitochondrial swelling caused by a wide diversity of chemical agents is preventable or reversible by $\mathrm{Mg}^{++} \mathrm{AT}$ Pase activity. $\mathrm{Mg}^{++}$occupies a central position in the structure and metabolism of myocardial cells. Hypoxia or hyperkalemia caused a substantial drop in intracellular myocardial $\mathrm{Mg}^{++}$. Myocardial loss of $\mathrm{Mg}^{++}$has also been reported in the infarcted area of the heart subsequent to experimental ligation of coronary artery. A fall in $\mathrm{Mg}^{++}$ content of the infarcted portion of the myocardium has been reported from the experimental animals and humans [7] [21] [68]-[75]. Myocardial contraction is due to cellular depolarization and $\mathrm{Ca}^{2+}$ plays an important role in excitation-contraction coupling. Subcellular $\mathrm{Ca}^{2+}$ transport in different areas of the dog heart had been reported by Dhalla et al. [68]-[75].

\subsubsection{Function of $\mathrm{Ca}^{2+}$ ATPase Activities}

The function of $\mathrm{Ca}^{2+}$ ATPase, like sarcoplasmic reticular $\mathrm{Ca}^{2+}$ ATPase, has been suggested to be involved in regulating the active efflux of Ca ions during relaxation of cardiac muscle. Since calcium efflux from the cardiac cell occurs against concentration gradient, there is possibility of calcium pump in heart sarcolemma. $\mathrm{Ca}^{2+}$ activated ATPase may be involved in the active efflux of calcium across the cardiac cell membrane by energy from hydrolysis of ATP by this enzyme. Dhalla et al. are of the opinion that $\mathrm{Ca}^{2+}$ ATPase activity is involved in the entry of $\mathrm{Ca}^{2+}$ into the cell, thereby participating in excitation-contraction coupling [18]. A significant reduction in $\mathrm{Ca}^{2+}$ ATPase activity in atria and ventricular tissue from $4 \mathrm{mg} / \mathrm{kg}$ scorpion venom treated rabbits and a significant increase in $\mathrm{Ca}^{2+}$ ATPase activity in ventricular tissue from $2 \mathrm{mg} / \mathrm{kg}$ venom treated rabbits suggest these animals suffered from intracellular deficits or an overloading of calcium ions, respectively. Alterations in $\mathrm{Ca}^{2+}$ ATPase activity from the sarcolemma are shown in different types of heart failure [7] [20] [21] [68]-[75].

It is suggested that acute myocarditis due to scorpion venom causes sarcolemmal defects. These are reflected in alterations in cardiac sarcolemmal ATPase activities. These sarcolemmal defects may be responsible for the subsequent pathological conditions.

\subsubsection{Clinical and Therapeutic Significance of the $\mathrm{Na}^{+}, \mathrm{K}^{+} \mathrm{Pump}$}

The $\mathrm{Na}^{+}, \mathrm{K}^{+}$ATPase or $\mathrm{Na}^{+}, \mathrm{K}^{+}$pump, mediating the active transport of $\mathrm{Na}^{+}$and $\mathrm{K}^{+}$, which was first identified 65 years ago, is a central target for acute and long-term regulation, as well as for therapeutic intervention [73] [79]-[81].

Acute stimulation of the $\mathrm{Na}^{+}, \mathrm{K}^{+}$ATPase in skeletal muscle by insulin increases the intracellular uptake of $\mathrm{K}^{+}$. Down regulation or inhibition of the $\mathrm{Na}^{+}, \mathrm{K}^{+}$ATPase is seen in scorpion envenoming syndrome, cardiac insufficiency and $\mathrm{K}^{+}$deficiency.

Down regulation or inhibition of the $\mathrm{Na}^{+}, \mathrm{K}^{+}$ATPase or $\mathrm{Na}^{+}, \mathrm{K}^{+}$pump, in skeletal muscle interferes with contractile performance [73] [79]-[81].

In cardiac insufficiency, the decrease in the concentration of the $\mathrm{Na}^{+}, \mathrm{K}^{+}$ATPase in the myocardium is over a wide range correlated to the concomitant reduction in ejection fraction. The regulatory and pathophysiological changes in the activity and concentration of the $\mathrm{Na}^{+}, \mathrm{K}^{+}$ATPase are important for the contractile function of skeletal muscles and heart as well as for $\mathrm{K}^{+}$homoeostasis [79]-[81].

\subsubsection{Increased Catecholamines and Angiotensin Suppress \& Inhibit Insulin Secretion}

Increased Catecholamines and Angiotensin released due to scorpion envenoming syndrome suppress \& inhibit insulin secretion, increase glucagon and glucocorticoids secretion [22] [24] [25] [28] [30] [31] [33] [42]. Changes in insulin secretion could be responsible for cardiac sarcolemmal defects and inhibition of erythrocyte $\mathrm{Na}^{+}-\mathrm{K}^{+}$ATPase activities in the experimental animals and in a scorpion sting victim respectively [21] [30].

\subsection{6. $\mathrm{Na}^{+}-\mathrm{K}^{+}$Pump Regulation and Skeletal Muscle Contractility}

In skeletal muscle, excitation may cause loss of $\mathrm{K}^{+}$, increased extra cellular $\mathrm{K}^{+}$, intracellular $\mathrm{Na}^{+}$, and depolarization. Since these events interfere with excitability, the process of excitation can be self limiting. During work, the impending loss of excitability has to be counterbalanced by prompt restoration of $\mathrm{Na}^{+} \mathrm{K}^{+}$gradients. Since this is the major function of the $\mathrm{Na}^{+}-\mathrm{K}^{+}$pumps, it is crucial that their activity and capacity are adequate. This is achieved by 1) acute activation of the $\mathrm{Na}^{+}-\mathrm{K}^{+}$pumps, and 2) long term regulation of $\mathrm{Na}^{+}-\mathrm{K}^{+}$pump content or capacity. Activation of the $\mathrm{Na}^{+}-\mathrm{K}^{+}$pumps by hormones is slower and less pronounced. When muscles are inhibited by high $\left[\mathrm{K}^{+}\right]_{0}$ or low $\left[\mathrm{Na}^{+}\right]_{0}$, acute hormone- or excitation—induced activation of the $\mathrm{Na}^{+}-\mathrm{K}^{+}$pumps can 
restore excitability and contractile force in $10-20$ min. Conversely, inhibition of the $\mathrm{Na}^{+}-\mathrm{K}^{+}$pumps by ouabaindigitalis leads to progressive loss of contractility and endurance [79]-[81].

$\mathrm{Na}^{+}-\mathrm{K}^{+}$pump content is down regulated during $\mathrm{K}+$ deficiency, hypoxia, heart failure and insulin deficiency.

Reduced $\mathrm{Na}^{+}-\mathrm{K}^{+}$pump activity leads to loss of contractility, endurance, and may contribute to fatigue.

Excitability and contractility depend on the ratio between passive $\mathrm{Na}^{+}-\mathrm{K}^{+}$leaks and $\mathrm{Na}^{+}-\mathrm{K}^{+}$pump activity, the passive leaks often playing a dominant role. The $\mathrm{Na}^{+}-\mathrm{K}^{+}$pump is a central target for regulation of $\mathrm{Na}^{+}-\mathrm{K}^{+}$ distribution and excitability, essential for second-to-second ongoing maintenance of excitability of skeletal muscle [79]-[81].

\section{Administration of Insulin}

Administration of insulin under these circumstances should counter-act the metabolic effects of catecholamines, stimulate lipogenesis, glycogenesis, reverse the metabolic and electrocardiographic changes in acute myocarditis induced by Indian red scorpion (Buthus tamulus) venom in the experimental dogs [26] [33].

\section{The Dose of Insulin in Scorpion Sting Victims}

The dose of insulin is 0.3 Units of regular insulin per gram of glucose, and glucose $0.1 \mathrm{~g} \cdot \mathrm{Kg}^{1}$ per hour. Blood glucose, serum electrolytes, electrocardiogram, and arterial blood gases should be investigated on admission. In addition to regular clinical observations, estimations of blood glucose should be carried out two hourly and of serum electrolytes 12-hourly. Glucose levels should be maintained between 130 and $180 \mathrm{mg} \cdot \mathrm{dl}^{1}$ of blood.

Scorpion envenoming in our hands resulted in a significant reduction in insulin and triglyceride levels and an increase in glucose and free fatty acid levels in animals after venom injection along with depletion of glycogen content in the cardiac and skeletal muscle and more depletion of glycogen content in the liver [9] [10] [22]-[25] [27] [28] [30] [32] [33] [37].

Insulin administration produced a reduction in FFA, an increase in triglyceride levels and increased tissue glycogen content in cardiac and skeletal muscle and that of liver [30] [33].

Catecholamines suppress insulin secretion [40] [41]. This could be the reason for reduction in the circulating insulin levels in the dogs after venom injection [9] [10] [22]-[29] [32] [35] [39].

Catecholamines released at sympathetic nerve endings and insulin deficiency thus produced can activate the hormone sensitive lipase, promote free fatty acid mobilization and produce a sudden increase in free fatty acid levels. This could be the reason for a sudden increase in FFA levels after venom injection [9] [10] [22]-[29] [32] [35] [39].

Utilization of increased amounts of circulating FFA result in increased myocardial oxygen consumption and this could aggravate the hypoxia in infracted myocardium predisposing to arrhythmias and heart failure. The elevated FFA increase the susceptibility of the ventricles to disorganized electrical behavior and produce ectopic beats in the vulnerable period of cardiac cycle. High levels of FFA observed under these pathological conditions produce inhibition of $\mathrm{Na}^{+}-\mathrm{K}^{+}$stimulated ATPase activity, cardiac sarcolemmal defects and these could also lead to arrhythmias [20] [21] [68]-[75]. Probably because of these mechanisms, cardio-tonics like digitalis are not beneficial in scorpion sting victims.

Moreover, there may be an increased tendency for intravascular thrombus formation because of the effects of FFA on platelet function producing disseminated intravascular coagulation [38] [39].

Rise in catecholamines and deficient insulin secretion enhance glycogenolysis. This could be the reason for depletion of glycogen content of atria, ventricles, liver and skeletal muscles [9] [10] [22]-[29] [32] [35] [39].

Insulin administration suppresses the release of FFA from adipose tissue and this effect is immediate and even faster than the effect on plasma glucose levels [30] [33].

Insulin stimulates lipogenesis [30] [33]. This could be the reason for the sudden reduction of free fatty acid levels and increased triglyceride levels in the venom poisoned animals after administration of insulin. Moreover, infusion of glucose in these animals along with insulin, will suppress fat mobilization by favoring re-esterification.

Insulin stimulates glycogen synthesis [30] [33]. Thus insulin counter-acts the effects of catecholamines favoring glucose uptake and inhibition of glucose release from liver. This could be the reason for an increased glycogen content of atria, ventricle, liver and skeletal muscle after insulin administration [30] [33]-[35] [37]. 


\title{
8. The Following Medicines Are Either Not Useful or Contra-Indicated in Scorpion Envenoming Syndrome
}

\author{
1) Cardiac glycosides, \\ 2) Atropine, \\ 3) Diuretics, \\ 4) Corticosteroids, \\ 5) Beta-blockers, \\ 6) Emetine hydrochloride (with local xylocaine injection), \\ 7) Adrenaline (with local xylocaine injection), \\ 8) Angiotensin Converting Enzyme (ACE) inhibitors.
}

\subsection{Cardiac Glycosides}

The cardiac glycosides are not effective in pulmonary oedema in the presence of sinus Tachycardia and normal cardiac size. The cardiac glycosides are known to act by inhibiting $\mathrm{Na}^{+}-\mathrm{K}^{+}$ATPase activity. The scorpion venom produces cardiac sarcolemmal defects displayed as inhibition of $\mathrm{Na}^{+}-\mathrm{K}^{+}$ATPase activity.

\subsection{Atropine}

Atropine should not be given routinely. This has been the common practice because of heavy perspiration and increased salivation.

Atropine may intensify the tachycardia and sympathetic effects due to the venom after blocking the cholinergic effects.

Atropine potentiates hypertensive effect.

Moreover, atropine is a parasympatholytic drug and inhibits insulin secretion from endocrine pancreas.

Increase in duration as well as severity of clinical signs, including myocardial injury were observed in scorpion sting victims treated with atropine compared to scorpion sting victims who did not receive atropine.

Atropine increases the severity of pulmonary oedema induced by scorpion toxin.

\subsection{Diuretics}

Diuretics are contraindicated, owing to their dehydrating effect, alteration in blood viscosity and stimulation of rennin-angiotensin secretion.

\subsection{Corticosteroids}

Glucocorticoids are contraindicated because they are catabolic hormones and anti-insulin in action. They stimulate the rennin-angiotensin system. Moreover, glucocorticoids act like, "asbestos suit against fire but they themselves do not extinguish the fire", and in the absence of specific drugs, glucocorticoids are likely to spread the inflammation. Besides, glucocorticoids are contra-indicated in non-cardiogenic pulmonary oedema.

\subsection{Angiotensin Converting Enzyme (ACE) Inhibitors}

Captopril is an angiotensin-converting enzyme inhibitor that inhibits the conversion of the relatively inactive angiotensin I to the active angiotensin II. It also inhibits the degradation of bradykinin and potentiates its hypotensive action. It is used in the management of hypertension, congestive heart failure and hypertensive emergencies. Captopril and other angiotensin-converting enzyme inhibitors are inferior to other vasodilators in the treatment of heart failure. Ismail, however, cautioned against the use of Captopril since the drug inhibits kininase enzyme and thus would lead to the accumulation of bradykinin, the neuro humoral agent, incriminated experimentally for the pulmonary oedema of the scorpion envenoming syndrome [7] [16]-[19].

\subsection{Adrenaline (with Local Xylocaine Injection)}

Scorpion venom is known to an autonomic storm releasing massive quantities of catecholamine hence adrenaline (with local xylocaine injection) is contraindicated. 


\subsection{Conclusions}

Scorpion envenoming syndrome is due to autonomic storm releasing massive quantities of catecholamines, angiotensin II, glucagon, Cortisol and either suppressed insulin secretion, or hyper-insulinemia/insulin resistance (failure of the actions of internally secreted insulin). The metabolic actions of all these hormones cause suppressed insulin secretion, or hyper-insulinemia/insulin resistance resulting in hyperglycemia and sudden increase in Free Fatty Acids. Severe scorpion envenoming syndrome is a syndrome of fuel-energy deficits and an inability of the vital organs to utilize the existing metabolic substrates. This ultimately may result in Multi-SystemOrgan Failure (MSOF) and death. Sudden increase in Free Fatty Acids cause sarcolemmal defects reflected in alterations in cardiac sarcolemmal ATPase activities of $\mathrm{Na}^{+}-\mathrm{K}^{+}$ATPase, $\mathrm{Mg}^{++}$ATPase and Ca ${ }^{2+}$ ATPase activities. These sarcolemmal defects may be responsible for the subsequent pathological conditions.

Insulin-glucose infusion resulted in glycogenesis, lipogenesis, stopped arrhythmias and reversed the ECG changes to sinus rhythm in the scorpion envenomed animals and in the scorpion sting victims. Insulin administration following scorpion envenoming reversed the ECG and metabolic changes in the experimental animals as well as in scorpion sting victims.

It can be concluded, that, the administration of insulin-glucose infusion should be recommended as the first choice therapy given as soon as possible, immediately after hospitalization in intensive care units to envenomed scorpion sting victims whose clinical picture is dominated by pulmonary oedema, cardiovascular, and many other clinical manifestations.

\section{References}

[1] Murthy, K.R.K. (2014) Enzymes and Toxins in Scorpions of Buthidae Family. Insulin-Glucose Administration Reverses Metabolic, Cardiovascular, ECG Changes and Pulmonary Edema in Scorpion Envenoming Syndrome. International Journal Medicine and Biosciences, 3, 9-25. http://www.ijmbonline.com/

[2] Murthy, K.R.K. (2014) Hematological Changes in Acute Myocarditis Due to Scorpion Envenoming Syndrome. International Journal of Chemical and Life Sciences, 3, 111-126. http://www.ijcls.com/

[3] Murthy, K.R.K. and Ravi, B.P. (2014) Laryngeal Spasm in Scorpion Envenoming Syndrome. Indian Journal of Mednodent and Allied Sciences, 2, 41-48. http://dx.doi.org/10.5958/j.2347-6206.2.1.008

[4] Murthy, K.R.K. (2014) Hypertension, Autonomic Storm, Increased Counter Regulatory Hormones and Suppressed Insulin Acute Myocarditis in Scorpion Envenoming Syndrome. World Journal of Cardiovascular Diseases, 4, 189-210. http://www.scirp.org/journal/wjcd http://dx.doi.org/10.4236/wjcd.2014.44027

[5] Amaral, C.F.S. and Rezende, N.A. (1997) Both Cardiogenic and Non-Cardiogenic Factors Are Involved in the Pathogenesis of Pulmonary Oedema after Scorpion Envenoming. Toxicon, 35, 997-998. http://dx.doi.org/10.1016/S0041-0101(96)00206-1

[6] Amaral, C.F.S., Barbosa, A.J.A., Leite, V.H.R., Tafuri, W.L. and de Rezende, N.A. (1994) Scorpion Sting-Induced Pulmonary Oedema: Evidence of Increased Alveolocapillary Membrane Permeability. Toxicon, 32, 999-1003. http://dx.doi.org/10.1016/0041-0101(94)90378-6

[7] Bahloul, M., Rekik, N., Chabchoub, I., Chaari, A., Ksibi, H., Damak, H., Chaari, A., Hamida, C.B., Chelly, H. and Bouaziz, M. (2001) Neurological Complications Secondary to Severe Scorpion Envenomation. Medical Science Monitor, 11, CR196-202.

[8] Bagchi, S. and Deshpande, S.B. (2001) Scorpion (Buthus tamulus) Venom Toxicity on Cardiopulmonary Reflexes Involves Kinins via 5-HT $\mathrm{HT}_{3}$ Receptor Subtypes. Journal of Venomous Animals and Toxins, 7, 25-44. http://dx.doi.org/10.1590/S0104-79302001000100003

[9] Balasubramaniam, P. and Murthy, K.R.K. (1981) Abnormal Cardiovascular and Electrocardiographic Profile and Cardiac Glycogen Content in Rabbits Injected with Scorpion Venom. Indian Journal of Physiology and Pharmacology, 25, 351-355.

[10] Balasubramaniam, P. and Murthy, K.R.K. (1984) Liver Glycogen Depletion in Acute Myocarditis Produced by Scorpion (Buthus tamulus) Venom. Indian Heart Journal, 36, 101-104.

[11] Bartholomew, C. (1970) Acute Scorpion Pancreatitis in Trinidad. British Medical Journal, 1, 666-668. http://dx.doi.org/10.1136/bmj.1.5697.666

[12] Bucaretchi, F., Baracat, E.C., Nogueira, R.J., Chaves, A., Zambrone, F.A., Fonseca, F.A. and Tourinho, F.S. (1995) A Comparative Study of Severe Scorpion Envenomation in Children Caused by Tityus bahiensis and Tityus serrulatus. Revista do Instituto de Medicina Tropical de São Paulo, 37, 331-336. 
http://dx.doi.org/10.1590/S0036-46651995000400008

[13] Freire-Maia, L., Campos, J.A. and Amaral, C.F.S. (1994) Approaches to the Treatment of Scorpion Envenoming. Toxicon, 32, 1009-1014. http://dx.doi.org/10.1016/0041-0101(94)90382-4

[14] Gueron, M., Adolph, R., Gruff, L., Grup, O., Gabel, M. and Fowler, N.O. (1980) Hemodymamics and Myocardial Consequences of Scorpion Venom. The American Journal of Cardiology, 45, 979-986. http://dx.doi.org/10.1016/0002-9149(80)90166-6

[15] Gueron, M., Ilias, R., Shahak, E. and Sofer, S. (1992) Renin and Aldosterone Levels Following Envenoming by Leiurus quinquestriatus. Toxicon, 30, 765-767. http://dx.doi.org/10.1016/0041-0101(92)90010-3

[16] Ismail, M. and Abd-Elsalam, M.A. (1988) Are the Toxicological Effects of Scorpion Envenomation Related to Tissue Venom Concentration? Toxicon, 26, 233-256. http://dx.doi.org/10.1016/0041-0101(88)90215-2

[17] Ismail, M., Fatani, A.Y. and Dabeas, T.T. (1992) Experimental Treatment Protocols for Scorpion Envenomation: A Review of Common Therapies and on Effect of Kallikrein-Kinin Inhibitors. Toxicon, 30, 1257-1279. http://dx.doi.org/10.1016/0041-0101(92)90442-8

[18] Ismail, M. (1993) Serotherapy of the Scorpion Envenoming Syndrome Is Irrationally Convicted without Trial. Toxicon, 31, 1077-1083. http://dx.doi.org/10.1016/0041-0101(93)90123-Z

[19] Ismail, M. (1995) The Scorpion Envenoming Syndrome. Toxicon, 33, 825-858. http://dx.doi.org/10.1016/0041-0101(95)00005-7

[20] Murthy, K.R.K. and Saxena, I.D. (1979) Investigations on Sarcolemmal ATPase Activities in Ventricular Tissues of Swimming Trained and Sedentary Rats. Indian Journal of Experimental Biology, 17, 277-280.

[21] Murthy, K.R.K. (1982) Investigations of Cardiac Sarcolemmal ATPase Activity in Rabbits with Acute Myocarditis Produced by Scorpion (Buthus tamulus) Venom. Japanese Heart Journal, 23, 835-842. http://dx.doi.org/10.1536/ihj.23.835

[22] Murthy, K.R.K. and Anita, A.G. (1986) Reduced Insulin Secretion in Acute Myocarditis Produced by Scorpion (Buthus tamulus) Venom. Indian Heart Journal, 38, 467-469.

[23] Murthy, K.R.K. and Haghnazari, L. (1999) Blood Levels of Glucagon, Cortisol and Insulin Following Scorpion (Mesobuthus tamulus concanesis, Pocock) Envenoming in Dogs. Journal of Venomous Animals and Toxins, 5, 47-55.

[24] Murthy, K.R.K., Billimoria, F.R., Khopkar, M. and Dave, K.N. (1986) Acute Hyperglycemia and Hyperkalemia in Acute Myocarditis Produced by Scorpion (Buthus tamulus) Venom Injection in Dogs. Indian Heart Journal, 38, 71-74.

[25] Murthy, K.R.K., Dubey, A.S., Abbas, Z.M. and Haghnazari, L. (2003) Investigations on the Role of Insulin and Scorpion Antivenom in Scorpion Envenoming Syndrome. Journal of Venomous Animals and Toxins Including Tropical Diseases, 9, 202-238.

[26] Murthy, K.R.K. and Hossein, Z. (1986) Increased Osmotic Fragility of Red Cells after Incubation at $37^{\circ} \mathrm{C}$ for 24 Hours in Dogs with Acute Myocarditis Produced by Scorpion (Buthus tamulus) Venom. Indian Journal of Experimental Biology, 38, 206-210.

[27] Murthy, K.R.K. and Medh, J.D. (1986) Increase in Serum Free Fatty Acids. Phospholipids and Reduction in Total Cholesterol in Acute Myocarditis Produced by Scorpion (Buthus tamulus) Venom. Indian Heart Journal, 38, 369-372.

[28] Murthy, K.R.K. and Vakil, A.E. (1988) Elevation of Plasma Angiotensin Levels in Dogs by Indian Red-Scorpion (Buthus tamulus) Venom and Its Reversal by Administration of Insulin and Tolazoline. Indian Journal of Medical Research, 88, 376-379.

[29] Murthy, K.R.K. and Yeolekar, M.E. (1986) Electrocardiographic Changes in Acute Myocarditis Produced by Scorpion (Buthus tamulus) Venom. Indian Heart Journal, 38, 206-210.

[30] Murthy, K.R.K., Vakil, A.E., Yeolekar, M.E. and Vakil, Y.E. (1988) Reversal of Metabolic and Electrocardiographic Changes Induced by Indian Red Scorpion (Buthus tamulus) Venom by Administration of Insulin, Alpha Blocker and Sodium Bicarbonate. Indian Journal of Medical Research, 88, 450-457.

[31] Murthy K.R.K., Anita, A.G., Dave, B.N. and Billimoria, F.R. (1988) Erythrocyte $\mathrm{Na}^{+}-\mathrm{K}^{+}$ATPase Activity Inhibition and Increase in Red Cell Fragility in Experimental Myocarditis Produced by Indian Red Scorpion Venom. Indian Journal of Medical Research, 88, 536-540.

[32] Murthy, K.R.K., Medh, J.D., Dave, B.N., Vakil, Y.E. and Billimoria, F.R. (1990) Acute Pancreatitis and Reduction of $\mathrm{H}^{+}$Ion Concentration in Gastric Secretions in Experimental Acute Myocarditis Produced by Indian Red Scorpion (Buthus tamulus) Venom. Indian Journal of Experimental Biology, 27, 242-244.

[33] Murthy, K.R.K., Vakil, A.E. and Yeolekar, M.E. (1990) Insulin Administration Reverses the Metabolic and Electrocardiographic Changes Induced by Indian Red Scorpion (Buthus tamulus) Venom in the Experimental Dogs. Indian Heart Journal, 48, 35-42.

[34] Murthy, K.R.K., Shenoi, R., Vaidyanathan, P., Kelkar, K., Sharma, N., Neeta, B., Rao, S. and Mehta, M.N. (1991) In- 
sulin Reverses Haemodynamic Changes and Pulmonary Oedema in Children Stung by Indian Red Scorpion Mesobuthus tamulus concanesis, Pocock. Annals of Tropical Medicine and Parasitology, 85, 651-657.

[35] Murthy, K.R.K. (2000) The Scorpion Envenoming Syndrome: A Different Perspective. The Physiological Basis of the Role Insulin in Scorpion Envenoming. Journal of Venomous Animals and Toxins, 6, 04-51.

[36] Murthy, K.R.K. (2013) Treatment of Scorpion Envenoming Syndrome-Need for Scientific Magnanimity. Journal of Indian Medical Association, 111, 254-259.

[37] Yugandhar, B., Murthy, K.R.K. and Sattar, S.A. (1999) Insulin Administration in Severe Scorpion Envenoming. Journal of Venomous Animals and Toxins, 5, 200-219. http://dx.doi.org/10.1590/S0104-79301999000200007

[38] Devi, S., Reddy, C.N., Devi, S.L., Subramaniam, Y.R., Murthy, D.P. and Reddy, C.R. (1970) Defibrination Syndrome Due to Scorpion Poisoning. British Medical Journal, 1, 345-347. http://dx.doi.org/10.1136/bmj.1.5692.345

[39] Murthy, K.R.K., Hossein, Z., Medh, J.D., Kudalkar, J.A., Yeolekar, M.E., Pandit, S.P., Khopkar, M., Dave, K.N. and Billimoria, F.R. (1988) Disseminated Intravascular Coagulation \& Disturbances in Carbohydrate and Fat Metabolism in Acute Myocarditis Produced by Indian Red Scorpion (Buthus tamulus) Venom. Indian Journal of Medical Research, 87, 318-325.

[40] Ganong, W.G. (1987) Review of Medical Physiology. 13rd Edition, Appleton and Lange, New York, 283.

[41] Keele, C.A., Neil, E. and Joels, N. (2000) Samson Wright’s Applied Physiology. 13rd Edition, Oxford University Press, Oxford, 405-512.

[42] Jackson, E.K. (2006) Renin and Angiotensin Goodman \& Gilman's the Pharmacological Basis of Therapeutics. 11st Edition, Brunton, L.L., Lazo, J.S. and Parker, K.L., Eds., McGraw-Hill Medical Publishing Division, New York, New Delhi, 795.

[43] Cecil (1976) Textbook of Medicine. 15th Edition, Beason, P.B., McDermott, W. and Wyngaarden, J.B., Eds., WB Saunders Co., Philadelphia \& Heinemann, London, 485.

[44] Braunwald’s Heart Disease (2011) Acute Myocarditis. 9th Edition, Bonow, R.O., Mann, D.L., Zipes, D.P. and Libby, P., Eds., Elsevier Saunder, Philadelphia, 1602-1610.

[45] Oxford Textbook of Medicine (2003) Injuries, Envenoming, Poisoning, and Allergic Reactions Caused by Animals. 4th Edition, Vol. 1, Warrel, D.A., Cox, T.M. and Firth, J.D., Eds., Oxford University Press, Oxford, 941-946.

[46] Davidson’s Principles \& Practice of Medicine (2010) Envenoming. 21st Edition, Colledge, N.R., Walker, B.R. and Ralston, S.H., Eds., Churchill, Livingstone, Elsevier, 223-228.

[47] Kumar, P. and Clark, M. (2005) Scorpions. In: Kumar, P. and Clark, M., Eds., Clinical Medicine, Elsevier Saunders, Philadelphia, 1021.

[48] Current Medical Diagnosis \& Treatment (2012) Scorpion Stings. 51st Edition, McPhee, S.J. and Papadakis, M.A., Eds., McGraw Hill Lange, 1545.

[49] Rosen’s Emergency Medicine (2006) Concepts and Clinical Practice. In: Marx, J.A., Ed., Venomous Animals, Mosby Elsevier, 907-908.

[50] Maguire, J.H., Pollack, R.J. and Spielman, A. (2005) Ectoparasite Infestations and Arthropod Bites and Stings. In: Kasper, D.L., Braunwauld, E., Fauci, A., Hauser, S., Longo, D. and Jameson, J., Eds., Harrison's Principles of Internal Medicine, McGraw-Hill Medical Publishing Division, 2604.

[51] Poon, K.T. (1963) Treatment of Scorpion Sting. British Medical Journal, 1, 1016. http://dx.doi.org/10.1136/bmj.1.5336.1016-b

[52] Gueron, M., Stern, J. and Cohen, W. (1967) Severe Myocardial Damage and Heart Failure in Scorpion Sting. American Journal of Cardiology, 19, 719-725. http://dx.doi.org/10.1016/0002-9149(67)90477-8

[53] Sofer, S. and Gueron, M. (1988) Respiratory Failure in Children Following Envenomation by the Scorpion Leiurus quinquestriatus: Haemodynamic and Neurological Aspects. Toxicon, 26, 931-939. http://dx.doi.org/10.1016/0041-0101(88)90258-9

[54] Gueron, M., Marqulis, G. and Sofer, S. (1990) Echoardiographic and Radionuclide Angiographic Observations Following Scorpion Envenomation by Leiurus quinquestriatus. Toxicon, 28, 1005-1009. http://dx.doi.org/10.1016/0041-0101(90)90138-W

[55] Murthy, K.R.K. and Zare, A.Z. (2002) Scorpion Antivenom Reverses Metabolic, Electrocardiographic, and Hormonal Disturbances Caused by the Indian Red Scorpion Mesobuthus tamulus concanesis, Pocock Envenomation. Journal of Venomous Animals and Toxins Including Tropical Diseases, 8, 30-48.

[56] Murthy, K.R.K., Zare, A.Z. and Haghnazari, L. (1999) The Use of Serotheraphy to Reverse ECG and Cardiac Enzyme Changes Caused by Scorpion Mesobuthus tamulus concanesis, Pocock Envenoming. Journal of Venomous Animals and Toxins, 5, 154-171. http://dx.doi.org/10.1590/S0104-79301999000200004

[57] Duddin, A.A., Rambaud-Cousson, A., Thalji, A., Juabeh, I.I. and Abu-Libdeh, M. (1991) Scorpion Sting in Children in 
the Jerusalem Area: A Review of 54 Cases. Annals of Tropical Paediatrics, 11, 217-223.

[58] D’Suze, G., Comellas, A., Pesca, L., Sevci, K.C. and Sanchez-de-León, R. (1999) Tityus discrepans Venom Produces a Respiratory Distress Syndrome in Rabbits through an Indirect Mechanism. Toxicon, 37, 173-180. http://dx.doi.org/10.1016/S0041-0101(98)00180-9

[59] Johnson, D.G., Henry, D.P., Moss, J. and Williams, H.H. (1976) Inhibition of Insulin Released by Scorpion Toxin on Rat Pancreatic Islets. Diabetes, 25, 198-201. http://dx.doi.org/10.2337/diab.25.3.198

[60] Johnson, D.G. and Ensinck, J.W. (1976) Stimulation of Glucagon Secretion by Scorpion Toxin in the Perfused Rat Pancreas. Diabetes, 25, 645-649. http://dx.doi.org/10.2337/diab.25.8.645

[61] Douglas, W.W. (1986) Homeostasis: Body Changes in Trauma and Surgery. In: Sabiston Jr., D.C., Ed., Textbook of Surgery, WB Saunders, Philadelphia, 23-37.

[62] Bondy, P.K. and Rosenberg, L.E. (1980) Metabolic Control and Disease. 8th Edition, WB Saunders Co., Philadelphia/ London/ Toronto, p. 1621.

[63] Fyge, T., Cochran, K.M., Bacter, R.H. and Booth, E.M. (1971) Plasma Lipid Changes after Myocardial Infarction. The Lancet, 298, 997-1001.

[64] Izzo Jr., J.L. and Swislocki, L.M. (1991) Workshop III-Insulin Resistance: Is It Truly the Link? The American Journal of Medicine, 90, S26-S31. http://dx.doi.org/10.1016/0002-9343(91)90033-T

[65] Pandey, S.V. and Mead, J.F. (1968) Inhibition of Enzyme Activities by Free Fatty Acids. The Journal of Biological Chemistry, 243, 6180-6186.

[66] Vik-Mo, H. and Mjøs, O.D. (1981) Influence of Free Fatty Acids on Myocardial Oxygen Consumption and Ischemic Injury. The American Journal of Cardiology, 48, 361-367. http://dx.doi.org/10.1016/0002-9149(81)90621-4

[67] Goldstein, R.E., Abumrad, N.N., Wasserman, D.H. and Cherrington, A.D. (1995) Effects of an Acute Increase in Epinephrine and Cortisol on Carbohydrate Metabolism during Insulin Deficiency. Diabetes, 44, 672-681. http://dx.doi.org/10.2337/diab.44.6.672

[68] Dhalla, N.S., Das, P.K. and Sharma, G.P. (1978) Subcellular Basis of Cardiac Contractile Failure. Journal of Molecular and Cellular Cardiology, 10, 363-385. http://dx.doi.org/10.1016/0022-2828(78)90384-X

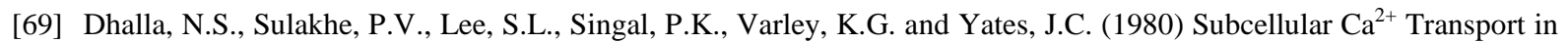
Different Areas of Dog Heart. Canadian Journal of Physiology and Pharmacology, 58, 360-367. http://dx.doi.org/10.1139/y80-062

[70] Dhalla, N.S., McNamara, D.B. and Anand, M.B. (1975) Heart Sarcolemma as a Dynamic Excitable Membrane. In: Roy, P.E. and Dhalla, N.S., Eds., Recent Advances in Studies on Cardiac Structure and Metabolism, The Sarcolemma, University Park Press, Baltimore, 1.

[71] Dhalla, N.S., Ziegelhoffer, A. and Harrow, J.A. (1977) Regulatory Role of Membrane Systems in Heart Function. Canadian Journal of Physiology and Pharmacology, 55, 1221-1234. http://dx.doi.org/10.1139/y77-167

[72] McNamara, D.B., Sulakhe, P.V., Singh, J.N. and Dhalla, N.S. (1974) Properties of Heart Sarcolemmal Na ${ }^{+}-K^{+}$ATPase. The Journal of Biochemistry, 75, 795-803.

[73] Skou, J.C. (1992) The $\mathrm{Na}^{+}-\mathrm{K}^{+}$Pump. News in Physiological Sciences, 7, 95-100.

[74] Sulakhe, P.V. and Dhalla, N.S. (1971) Excitation-Contraction Coupling in Heart VI. Demonstration of Calcium Activated ATPase in the Dog Heart Sarcolemma. Life Sciences, 10, 185-191. http://dx.doi.org/10.1016/0024-3205(71)90247-5

[75] Sulakhe, P.V. and Louis, P.J. (1980) Passive and Active Calcium Fluxes across Plasma Membranes. Progress in Biophysics and Molecular Biology, 35, 135-195. http://dx.doi.org/10.1016/0079-6107(80)90005-X

[76] Oliver, M.F. (1975) The Vulnerable Ischemic Myocardium and Its Metabolism. In: Oliver, M.F., Ed., Modern Trends in Cardiology, Butterworths, London, 280-291.

[77] Choudhary, P. (2006) Mechanism of Action of Insulin in Reversing the Indian Red Scorpion Envenomation in Rats. Thesis, Banaras Hindu University, Varanasi.

[78] Abdel-Haleem, A.H., Meki, A.R., Noaman, H.A. and Mohamed, Z.T. (2006) Serum Levels of IL-6 and Its Soluble Receptor, TNF- $\alpha$ and Chemochine RANTES in Scorpion Envenomed Children. Their Relation to Scorpion Envenomation Outcome. Toxicon, 47, 437-444. http://dx.doi.org/10.1016/j.toxicon.2005.12.008

[79] Clausen, T. (1986) Regulation of Active $\mathrm{Na}^{+}-\mathrm{K}^{+}$Transport in Skeletal Muscle. Physiological Review, 66, 542-580.

[80] Clausen, T. (1998) Clinical and Therapeutic Significance of the Na, K Pump. Clinical Science, 95, 3-17. http://dx.doi.org/10.1042/CS19970254

[81] Clausen, T. (2003) $\mathrm{Na}^{+}-\mathrm{K}^{+}$Pump Regulation and Skeletal Muscle Contractility. Physiological Review, 83, $1269-1324$. 
Scientific Research Publishing (SCIRP) is one of the largest Open Access journal publishers. It is currently publishing more than 200 open access, online, peer-reviewed journals covering a wide range of academic disciplines. SCIRP serves the worldwide academic communities and contributes to the progress and application of science with its publication.

Other selected journals from SCIRP are listed as below. Submit your manuscript to us via either submit@scirp.org or Online Submission Portal.
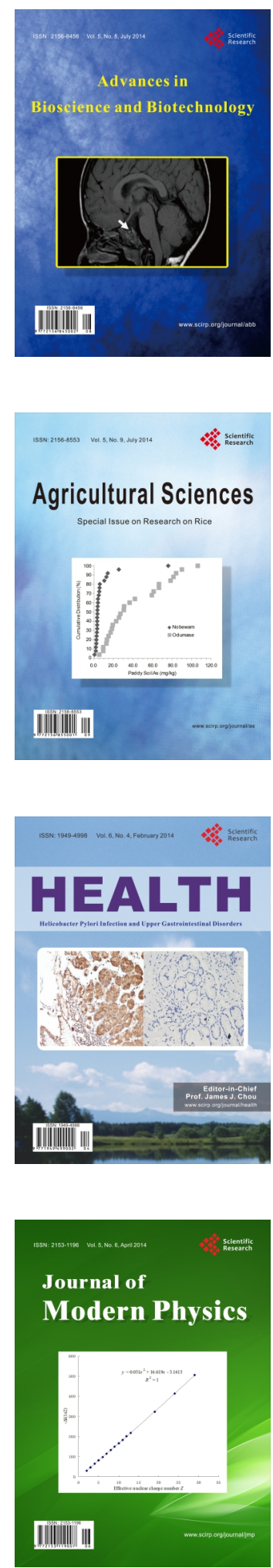
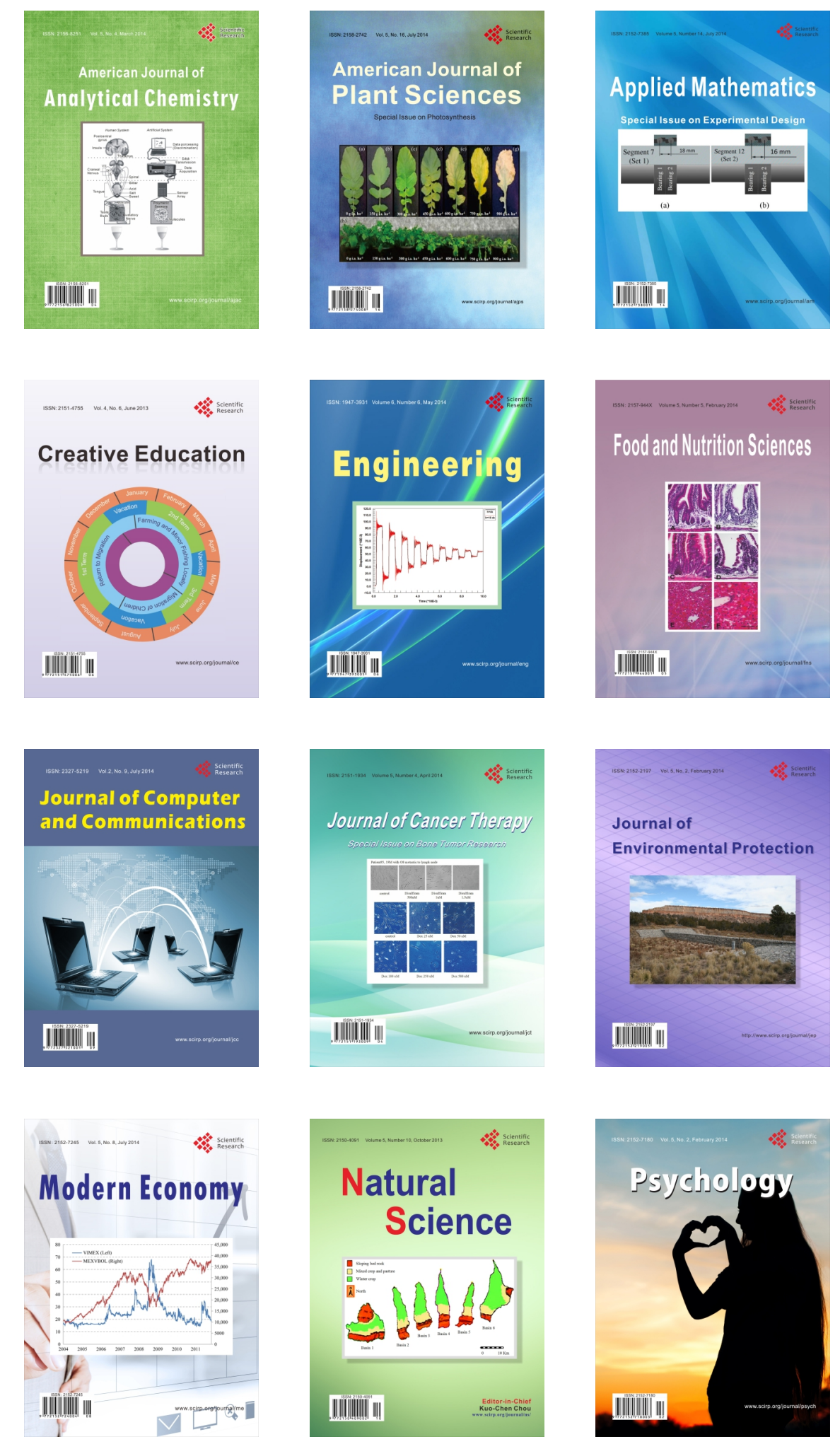